\title{
PRESERVICE EDUCATION IN AUGMENTATIVE AND ALTERNATIVE COMMUNICATION: AN UPDATE
}

By

\author{
Copyright 2018 \\ Kate DeJarnette \\ B.A., University of Kansas, 2016
}

Submitted to the graduate degree program in Speech-Language-Hearing: Sciences and Disorders and the Graduate Faculty of the University of Kansas in partial fulfillment of the requirements for the degree of Master of Arts.

Jane R. Wegner

Chairperson

Nancy Brady

Stephanie Meehan

Date Defended: April 27, 2018 
The Thesis Committee for Kate DeJarnette

Certifies that this is the approved version of the following thesis:

PRESERVICE EDUCATION IN AUGMENTATIVE AND ALTERNATIVE COMMUNICATION: AN UPDATE

Jane R. Wegner Chairperson

Date approved: April 27, 2018 


\begin{abstract}
This study assessed the characteristics of preservice education in augmentative and alternative communication (AAC) in Council on Academic Accreditation (CAA) graduate programs in speechlanguage pathology. A survey entitled "Preservice Education in AAC: An Update" was hosted online via Qualtrics software. Participation was solicited via email using contact information from graduate program websites. A total of 85 program directors, department chairs, clinical directors, and faculty members responded to the survey and provided information describing the characteristics of the graduate programs with which they are affiliated.
\end{abstract}

Data from this survey revealed that there has been a general trend towards an increase in the number of graduate programs that offer coursework in AAC, the number of graduate students who are receiving knowledge and skills in AAC, and the number of students who obtain clinical clock hours in AAC. However, results indicate that some graduate programs in speech-language pathology continue to face barriers in providing comprehensive preservice education in AAC. Specifically, some of these barriers include: limited funding, lack of faculty members with expertise in AAC, access to AAC systems and technologies, and time constraints.

Implications for graduate programs in speech-language pathology include a need to utilize creative problem-solving to overcome barriers in providing preservice education in AAC to its students. Suggestions of possible solutions to overcome these barriers include: a) building relationships with local AAC vendor representatives to create opportunities for long-term AAC system loans, opportunities for community-based student observations, and demonstrations of AAC competencies, b) utilizing technology and virtual meetings to collaborate with other graduate programs in speech-language pathology with a strong foundation in $\mathrm{AAC}$, and c) using telepractice to provide intervention services to individuals with complex communication needs who would not otherwise have access to AAC services. 


\section{Acknowledgements}

I would like to acknowledge the following people for their generous contributions, encouragement, and support during this project and throughout my graduate school experience. Each of these individuals, as well as countless others, has greatly influenced me and has helped to make this journey possible.

First, I would like to express my sincere gratitude to Jane Wegner, my advisor and mentor. Jane, thank you for your unwavering encouragement, gentle kindness, and guidance throughout the writing of this thesis and my graduate studies. You have embodied the definition of a role model, and your knowledge, perspective, and passion have helped to shape my career aspirations and my hopes to become a strong advocate for others.

To Nancy Brady and Stephanie Meehan, thank you for the time and support you have poured into this project and other aspects of my graduate studies. You both have supported my ambitions and have actively worked to provide me with support to pursue and achieve those goals.

To my friends in the program and the other members of the ACTS grant, this project would not have been possible without you all. You have taught me about patience, balance, and joy. You have pushed me to become a better version of myself, and for that I am truly grateful.

Finally, to my family, thank you for bringing me humor, comfort, and compassion to my life. I am very thankful to have a strong support system that has encouraged me throughout every step of this journey. 


\section{Table of Contents}

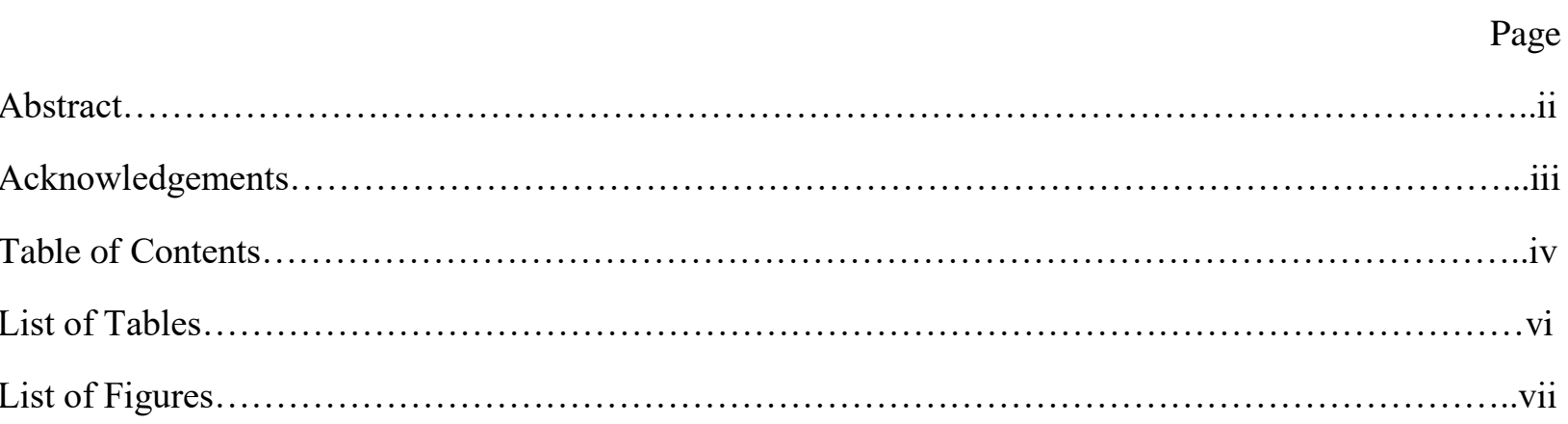

\section{CHAPTER I}

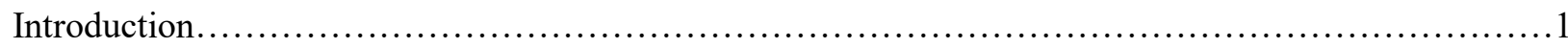

Augmentative and Alternative Communication.................................................

Roles and Responsibilities of Speech-Language Pathologists....................................

Knowledge and Skills in AAC ..............................................................

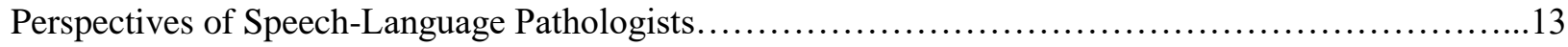

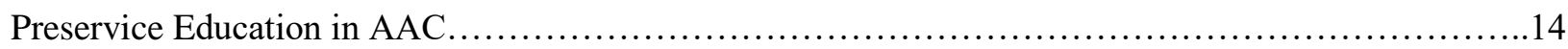

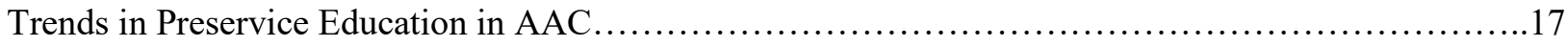

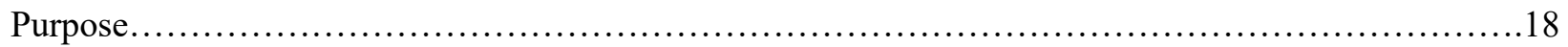

\section{CHAPTER II}

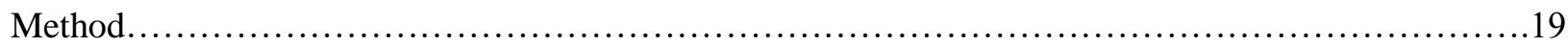

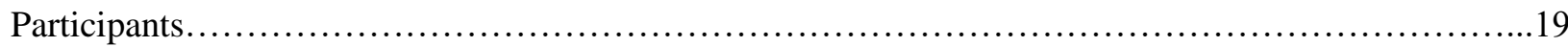

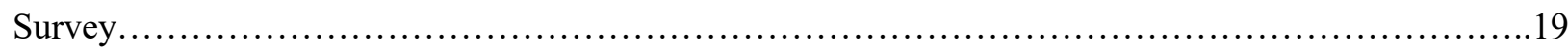

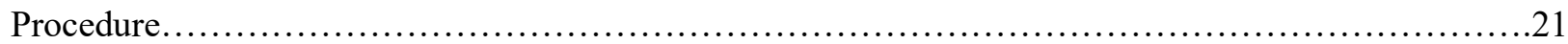

\section{CHAPTER III}

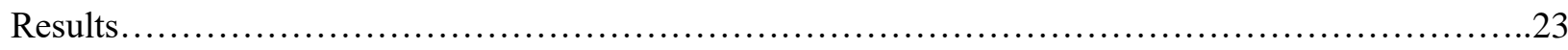

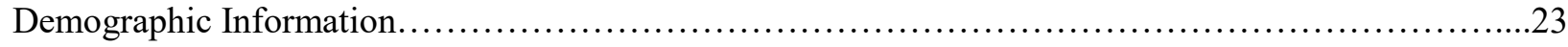

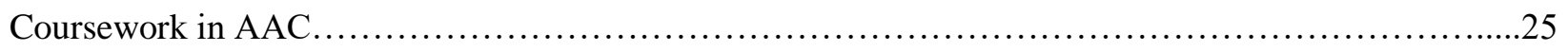

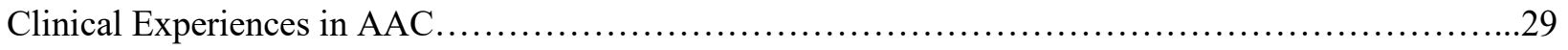

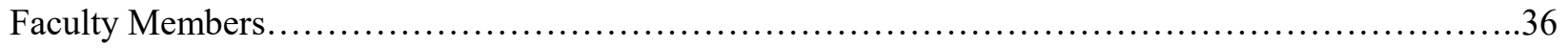


Additional Learning Opportunities in AAC

\section{CHAPTER IV}

Discussion.......................................................................... 42

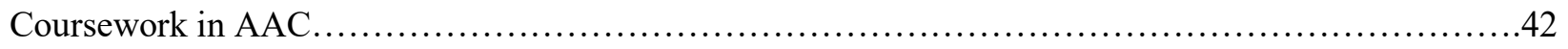

Clinical Experiences in AAC ............................................................ 44

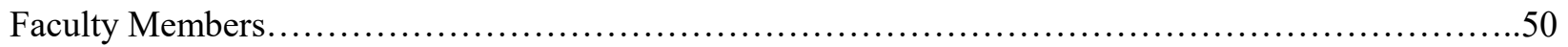

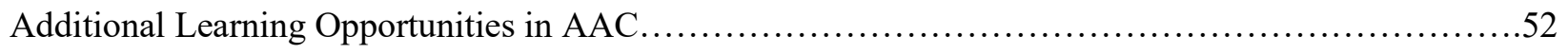

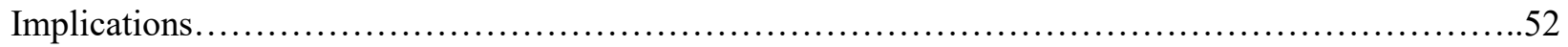

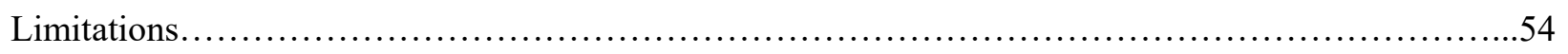

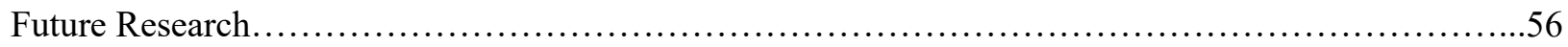

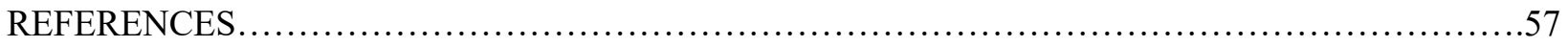

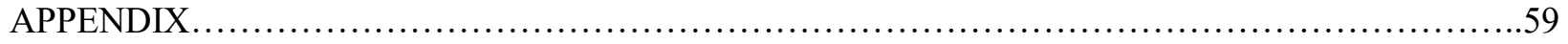


List of Tables

Table Page

1 Prevalence of AAC as Reported by Enderby et al. (2009).......................................

2 Participants' Position Within Their Graduate Program..........................................24

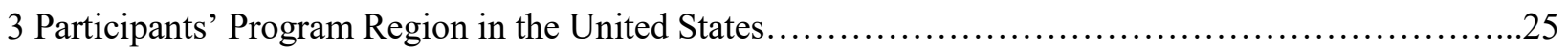

4 Amount of Classroom Time Devoted to AAC Content in Non-Dedicated Coursework.................27

5 Barriers Providing Comprehensive Coursework in AAC .......................................29

6 Types of Hands-On Experience in AAC Provided to Students in AAC Coursework....................30

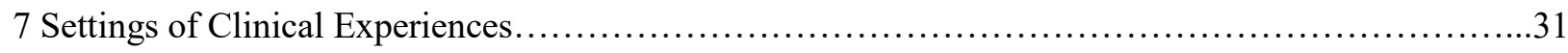

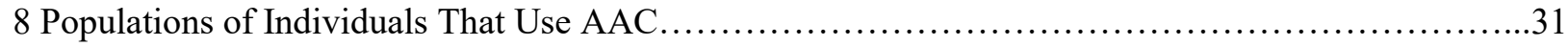

9 Percentage of Students That Graduate with Clinical Clock Hours in AAC ...........................33

10 Percentage of Students That Graduate with Knowledge and Skills in AAC .........................33

11 Comparison of Students That Graduate with Clock Hours in AAC and Presence of Onsite Systems...34

12 Barriers to Providing Comprehensive Clinical Experiences in AAC ............................ 35

13 Individuals Responsible for Teaching Coursework in AAC ......................................36

14 Comparison of Total Faculty Members and Faculty Members with Primary Expertise in AAC.......39

15 Barriers to Providing Comprehensive Preservice Education in AAC .............................40 


\section{List of Figures}

Figure Page

1 Academic/Tenure-Track Faculty Members Levels of Expertise in AAC .............................38

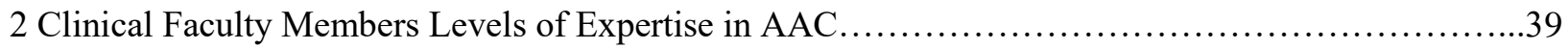




\section{CHAPTER I}

\section{Introduction}

In recent years, the field of speech-language pathology has been marked by an increase in awareness of the need to provide services to individuals with complex communication needs who utilize or could benefit from the use of augmentative and alternative communication (AAC) (Binger \& Light, 2006). According to Beukelman and Mirenda (2013), there are approximately 4 million Americansabout $1.3 \%$ of the nation's population — who are unable to meet their daily communication needs through natural or verbal speech. Although it is difficult to determine an exact number of individuals who use AAC, it is widely accepted that this number is growing (ASHA, n.d., b). This could be due to a variety of reasons including: a) an increased awareness about the need to provide AAC to a variety of individuals with disabilities, b) a growing number of individuals with complex communication needs who could benefit from AAC; which could be due, in part, to growing medical advances in neonatal care, and c) improvements in AAC technology (ASHA, n.d.; Light \& McNaughton, 2012; Binger \& Light, 2013, Ratcliff \& Beukelman, 1995; Koul \& Llyod, 1994). This increase in the number of individuals with complex communication needs who utilize or could benefit from AAC has impacted speech-language pathologists, as well as their clients with complex communication needs.

\section{Augmentative and Alternative Communication}

Augmentative and alternative communication (AAC) refers to "all forms of communications other than oral or verbal speech that are used to express thoughts, needs, wants, and ideas" (ASHA, n.d., para. 1). More specifically, AAC can refer to a variety of communication techniques, tools, and strategies, including: speech-generating devices (SGDs), low-tech picture communication boards, line drawings, tangible objects, gestures, and finger spelling. These forms of communication techniques, tools, and strategies are often divided into two broad categories: unaided forms of AAC and aided forms of AAC. According to ASHA (n.d., b), unaided forms of AAC do not require an external tool but may require some degree of motor control. Examples of unaided forms of AAC include: gestures, manual signs, facial expressions, verbalizations, vocalizations, and body language. Conversely, aided forms of AAC do 
require some degree of external support, which could be electronic or nonelectronic. Nonelectronic aids are often referred to as "low-tech" or "light-tech," whereas electronic forms are often referred to as "hightech.” Examples of low-tech aided AAC include: pictures, objects, photographs, writing, and picture communication boards or books. Examples of high-tech aided AAC include: SGDs, single-message devices and recordable/digitized devices, and AAC software that enables dynamic symbol/language representation and is used with some form of technology medium (ASHA, n.d., p. 2).

To meet the physical needs of some individuals with complex communication needs, many aided forms of AAC have a variety of selection techniques to access the system. Selection techniques refer to the ways an individual who uses AAC can access their communication system and its messages and/or symbols. Selection techniques are typically divided into two broad categories: direct selection and indirect selection. Direct selection refers to the selection technique where the individual who uses AAC selects their desired message or symbol directly from a selection set, using physical touch from a body part or external object. Direct selection may also refer to generated activation, where the individual uses a joystick, eyegaze technology, trackball, mouse, or brain-computer interface technology to select their desired message (ASHA, n.d., para. 6; Beukelman \& Mirenda, 2013. Indirect selection typically refers to the use of scanning, in which the AAC system presents each item from a selection set in a given sequence or pattern until the desired item appears. Then, the individual uses a switch, vocalization, or agreed-upon motor movement to indicate selection of the desired item (ASHA, n.d., p. 6; Beukelman \& Mirenda, 2013).

Individuals who use or could benefit from AAC include people of all ages, races, ethnicities, socioeconomic groups, and cultural backgrounds. Furthermore, AAC benefits individuals with a wide range of communication disorders, including developmental, congenital disorders and acquired disorders. Individuals with the following congenital disorders may be potential candidates for AAC: autism spectrum disorders, Down syndrome, developmental delays, intellectual disabilities, cerebral palsy, and childhood apraxia of speech. Individuals with the following acquired disorders may be potential 
candidates for AAC: stroke, traumatic brain injury (TBI), and amyotrophic lateral sclerosis (ALS). It is important to note that this is not an exhaustive list, and medical or communication diagnoses are not requisites to use AAC. According to Beukelman \& Mirenda (2013), "there is no typical person who relies on AAC. They come from all age groups, socioeconomic groups, and ethnic and racial backgrounds. Their only unifying characteristic is the fact that they require adaptive assistance for speaking and/or writing because their gestural, spoken, and/or written communication is temporarily or permanently inadequate to meet all of their communication needs" (p. 4). The inability to meet all daily communication needs through traditional communication, like verbal speech, is the only candidacy requirement for using AAC. There are no prerequisite skills for acquiring or using AAC (ASHA, n.d.).

Speech-language pathologists work with individuals to facilitate and support the development of communicative competence so individuals with complex communication needs are able to reliably and consistently access communication (Light \& McNaughton, 2014). With reliable access to the power of communication, individuals with complex communication needs can interact with others, influence and control their environments, seek academic ventures and gainful employment, and fully participate in society. However, when children or adults do not have access to a reliable form of communication, many become resigned to a limited means to express themselves, leading to limitations in developing relationships with others, and difficulty participating as an active member of their community (Light \& McNaughton, 2014).

To illustrate the substantial challenges that many individuals face, Light and McNaughton (2015) outlined statistics associated with children and adults with complex communication needs, including, but not limited to: a) $90 \%$ of students with complex communication needs enter adulthood without acquiring functional literacy skills - thereby inhibiting their educational achievement and diminishing their employment options, social networks, and access to independent living, b) less than $5 \%$ of individuals with complex communication needs are employed even part-time, at least in part due to a lack of reliable 
and effective communication, and c) the majority of these individuals do not have a means to communicate medical needs, provide medical information, or report instances of crime and abuse.

Light and McNaughton (2015) note that the ultimate goal of AAC intervention is to provide opportunities for children and adults with complex communication needs to live happy and fulfilled lives where they are able to participate fully in education, employment, and social aspects of life; where they feel safe and secure; where they have access to necessary or desired services; and much more. Communication is not an end goal in-and-of-itself, but rather, it is a tool to allow individuals to participate in their lives. Speech-language pathologists are key players in helping children and adults with complex communication needs gain access to the aforementioned types of reliable and effective communication. However, researchers in the field note that one of the major factors that negatively impacts the services given to individuals with complex communication needs is the lack of professionals that are trained in AAC (Light et al., 2012; Koul \& Llyod, 1994).

\section{Roles and Responsibilities of Speech-Language Pathologists in AAC}

According to the American Speech-Language-Hearing Association (ASHA, n.d., p. 9), speechlanguage pathologists "play a central role in the screening, assessment, diagnosis, and treatment of persons requiring AAC intervention. The professional roles and activities in speech-language pathology include clinical and educational services (diagnosis, assessment, planning, and treatment), advocacy, education, administration, and research.” Thus, speech-language pathologists have many roles and responsibilities related to serving individuals with complex communication needs; and they must have adequate competency in AAC to carry out each of these tasks.

AAC Assessment. The purposes of AAC assessment are to gather and analyze information related to an individual's current and future communication needs, the adequacy of current communication techniques, and how to provide instruction and intervention using the most appropriate AAC techniques (Beukelman \& Mirenda, 2013). This information is then used so individuals with 
complex communication needs and their support systems can make informed decisions regarding AAC use, strategies, and intervention plans. AAC assessment considers the strengths and needs of the individual, which may include: augmentative means of communicate to facilitate natural speech, alternative means of communication to replace natural speech or writing, temporary versus permanent need for AAC, and/or means of communication to facilitate more appropriate alternate behaviors (ASHA, n.d., p. 10).

AAC assessments often use a feature-matching process, wherein the AAC team administers criterion-referenced tasks that are intended to answer questions relevant to the strengths and needs of the individual with complex communication needs (Beukelman \& Mirenda, 2013). Using this information, the team members can make predictions about the AAC systems that are likely to be appropriate for the specific strengths and needs of the individual with complex communication needs. Then, the team sets up trial periods with each of the possible AAC systems and uses the information gained from each trial period to inform their recommendation of a specific AAC system (Beukelman \& Mirenda, 2013).

AAC assessment procedures and philosophies have varied throughout history. Decades ago, AAC assessment operated upon the Candidacy Model — a framework in which an individual with complex communication needs were required to have a set of skills and criteria to qualify for AAC. However, in the 1970s and 1980s, controversy arose around this model because it often left individuals with complex communication needs deprived of the ability to communicate because they were "too something" (e.g., too young, too cognitively impaired, too skilled with natural speech, etc.) or "not ready for" AAC (Beukelman \& Mirenda, 2013). In response to practices of the Candidacy Model, the National Joint Committee for the Communication Needs of Persons with Severe Disabilities issued a position statement (2003, para. 3) that stated, "eligibility determinations based on a priori criteria violate recommended practice principles by precluding consideration of individual needs." This statement gave way to a new era of AAC assessment, which operates on the Participation Model. This model provides a systematic 
process for conducting $\mathrm{AAC}$ assessments and creating AAC intervention plans, based upon the participation requires of age-matched individuals without disabilities (Beukelman \& Mirenda, 2013.

The Participation Model analyzes the individual's barriers to communication access and opportunities to plan short and long-term intervention through a four-phase process. Throughout these phases an individual is referred for an AAC assessment, then assessment and intervention plans are created by the team for both the immediate future, as well as the long-term (Beukelman, \& Mirenda, 2013). It is important to establish both an immediate and long-term intervention plan to accommodate communicative and health changes of the individual and associated needs for communication (Beukelman \& Mirenda, 2013). The Participation Model serves as a guide for AAC assessments and interventions. It also provides detailed information for the team members to evaluate access barriers and opportunity barriers that may inhibit an individual's success with an AAC system. Access barriers are defined as "pertaining to the capabilities, attitudes, and resource limitations of individuals who communicate through AAC, rather than to societal or support system limitations" (Beukelman \& Mirenda, 2013). Opportunity barriers refer to barriers that are imposed by external factors or persons other than the individual with complex communication needs. Opportunity barriers cannot be eliminated through the provision of an AAC system or intervention (Beukelman \& Mirenda, 2013). Assessing opportunity and access barriers aids in the creation of effective intervention and assessment plans. The AAC assessment process is often a team-effort, with possible team members including: the individual with complex communication needs, the individual's family and/or caregivers, the speech-language pathologist, occupational therapist, education professionals, and more. However, speech-language pathologists are often the lead team member throughout the AAC assessment process and should be informed on current best-practice procedures to ensure communicative success for the individual who uses AAC. In relation to AAC assessment, speech-language pathologists are responsible for,

screening individuals who may benefit from AAC intervention; determining the need for further assessment and/or referral for other services; conducting a comprehensive, transdisciplinary, 
culturally and linguistically appropriate assessment related to the provision of AAC services; involving individuals and family members in decision making to the greatest extent possible; serving as a liaison between the family and the SGD provider; generating reports to help with funding and collaborate with funding agencies; and knowing about funding sources and the requirements for applying for funding from each source. (ASHA, n.d., p. 9).

Considering these responsibilities, it is reasonable to infer that speech-language pathologists who are conducting AAC evaluations need to have the necessary knowledge and skills in AAC to conduct each of these components of the assessment process. These knowledge and skills have varied over time. As AAC assessment procedures and philosophies have changed throughout history, so have the necessary knowledge and skills needed to conduct a clinically competent assessment.

AAC Intervention. AAC interventions are intended to support individuals so they can meet their current and future communication needs (Beukelman \& Mirenda, 2013). In prior eras, AAC assessment and intervention services were based on prerequisite skill status. Many individuals with complex communication needs were required to "master" a set of arbitrary criteria in order to qualify for AAC services. However, in recent decades, AAC service delivery has rejected this premise and moved toward a zero-reject model wherein any individual who is unable to meet their daily communication needs is a potential candidate for AAC (Ratcliff \& Beukelman, 1995).

When providing intervention services to individuals with complex communication needs who use AAC, speech-language pathologists are responsible for,

involving individuals and family members in decision making throughout the intervention process; developing and implementing intervention plans that are culturally and linguistically appropriate to maximize effective communication between individuals who use AAC and their communication partners across the lifespan; counseling persons who use AAC and their families/caregivers regarding communication-related issues and providing education aimed at 
preventing abandonment and other complications related to AAC use; using evidence-based practice to evaluate functional outcomes of $\mathrm{AAC}$ intervention; ensuring that $\mathrm{AAC}$ goals and $\mathrm{AAC}$ use are included in a student's IEP; documenting progress, determining appropriate AAC modifications, and determining the dismissal and follow-up criteria, if indicated; educating other professionals and caregivers on the needs of persons using AAC and the role of speech-language pathologists in meeting the needs of individuals who use AAC; and advocating for individuals and their families/caregivers at the local, state, and national levels, particularly with regard to funding, education, and acceptance of AAC use. (ASHA, n.d., p. 16)

These guidelines highlight the breadth of activities that speech-language pathologists should participate in when providing intervention services to individuals who use AAC. Thus, this further demonstrates the need for speech-language pathologists to have acquired the necessary competencies required to carry out all responsibilities associated with AAC intervention services.

In accordance with the intervention roles and responsibilities of speech-language pathologists in AAC, following assessment, the speech-language pathologist works with the family, caregivers, and individual with complex communication needs to develop and implement and intervention plan. The speech-language pathologist often strives to educate important communication partners regarding AAC and its use. Using the Participation Model and the associated intervention plans for today and for tomorrow, the speech-language pathologist and other team members work to implement these short-term and long-term intervention plans. Interventions for today need to consider the person's immediate communication needs, as well as possible communicative opportunities that are non-fatiguing and efficient (Beukelman \& Mirenda, 2013). Interventions for tomorrow should focus on broadening the person's skill set, in anticipation of their future communicative needs and abilities. To provide these types of services to individuals with complex communication needs, speech-language pathologists must possess the appropriate knowledge and skills in AAC. 
Conduction of ethical AAC assessment and intervention services can involve a variety of individuals and professionals with varying levels of expertise in AAC. Binger et al. (2012) developed an AAC Assessment Personnel Framework to clarify professional roles and provide guidelines for AAC evaluations. This framework consists of nine personnel roles, including: a) AAC finder; b) General practice SLP; c) AAC clinical specialist; d) AAC facilitator; e) collaborating professional; f) AAC research/policy specialist; g) AAC manufacturer/vendor; h) AAC funding agency/funding personnel, and; i) AAC technology training agency personnel. These categories, while intended for the AAC assessment process, can also be applied to AAC intervention services. Many practicing speech-language pathologists would likely fall in the category of "general practice SLPs," wherein they provide a range of clinical services in hospitals, schools, private practices, and long-term care facilities, but do not specialize in AAC. According to Binger et al. (2012), many general practice speech-language pathologists are excellent team members for conducting AAC evaluations and carrying out AAC interventions, and thus must possess adequate knowledge and skills in AAC.

\section{Knowledge and Skills in AAC}

Considering these roles and responsibilities of speech-language pathologists in relation to AAC, it is reasonable to assume that these professionals are required to have significant knowledge and skills in AAC. Professionals who provide services to individuals with complex communication needs are required to understand a variety of techniques, strategies, technologies, supports, and characteristics of communication partners (Ratcliff, Koul, \& Llyod, 2008). Binger et al. (2012) note that "general practice speech-language pathologists," or clinicians who provide clinical services without expertise in AAC should possess knowledge and skills to deliver competent assessment and intervention services in AAC. Therefore, it is reasonable to posit that all speech-language pathologists - those whom do and do not possess expertise in AAC — should possess adequate knowledge and skills in AAC to be able to deliver clinically competent services to individuals with complex communication needs. Education and training 
in the area of AAC assessment and intervention is important for speech-language pathologists to service potential users of AAC (Ratcliff, Koul, \& Llyod, 2008).

ASHA's Code of Ethics (2016, p. 6) states that "speech-language pathologists shall engage in only those aspects of the profession that are within the scope of their professional practice and competence, considering their level of education, training, and experience.” This definition leaves determination of clinical competency in AAC up to the discretion of individual speech-language pathologists, which has a great clinical implication. It is possible that speech-language pathologists may deem themselves clinically-competent to practice in the area of AAC, despite having limited education and training in AAC; thereby providing less than adequate AAC assessment and intervention services to children and adults with complex communication needs. In addition to the possibility that service providers may not possess clinical competence in AAC, there is evidence that individuals who could benefit from AAC are not receiving speech and language services at all (Ratcliff \& Beukelman, 1995).

According to Speech Pathology Australia (2014), cited by Australia's Clinical Innovation and Governance group (2016), there are approximately 1.1 million Australians who have difficulty communicating via verbal speech, yet only 13,000 Australians use AAC devices. That means that approximately $1 \%$ of Australians with complex communication needs have access to AAC devices. Enderby et al. (2009) reviewed literature regarding the prevalence of AAC in the United States (US) and United Kingdom (UK). Table 1 represents the findings from this study. These findings indicate that individuals in the UK and US who could benefit from the use of AAC may not actually have access to it. However, there is a need for additional research to document more accurate information comparing the number of individuals who could benefit from AAC to the number of individuals who actually have access to AAC. 
Table 1

Prevalence of AAC as Reported by Enderby et al. (2009)

\begin{tabular}{ll} 
Population Referred to & Prevalence \\
\hline Children and young people needing high technology & $0.05 \%$ or 6,200 people \\
AAC in the UK & \\
\hline UK population who would benefit from AAC & $\begin{array}{l}0.4-1 \% \\
0.6 \% \text { most quoted }\end{array}$ \\
\hline People in UK and US who require AAC systems & $0.3-1.4 \%$ \\
& \\
\hline School population in UK needing AAC systems & $0.2-0.6 \%$ \\
& \\
\hline & \\
Children with Special Educational Needs statement in & $18 \%$ \\
&
\end{tabular}

People in US using AAC systems $\quad$ 8-12 people per $1000(0.008-0.012 \%)$

Recent studies note that between $45 \%$ and $62 \%$ of practicing professionals provide services to individuals with complex communication needs (Costigan \& Light, 2010; Ratcliff, Koul, \& Llyod, 2008; Marvin et al., 2003; Johnson et al., 2006). A study conducted by Simpson et al. (1998) found that schoolbased speech-language pathologists in Nebraska averaged 6 students who required AAC per caseload. A study conducted by Binger and Light (2006) had similar findings, noting that — on average — nearly onefourth of the children on the caseloads of early-intervention speech-language pathologists in Pennsylvania required AAC $(n=7)$. These numbers indicate the need for all speech-language pathologists to be prepared to provide AAC services to preschool and school-aged children. Given the likelihood of providing services to individuals with complex communication needs, speech-language pathologists must have at least basic knowledge and skills in AAC (Costigan \& Light, 2010).

Despite the need to obtain and maintain knowledge and skills in AAC, many practicing professionals feel as though they do not possess adequate competencies for service provision and report their discomfort with providing services in AAC (Ratcliff, Koul, \& Llyod, 2008; Marvin et al, 2003; Simpson, Beukelman, \& Bird, 1998; Gorenflo \& Gorenflo, 1990). 
Marvin et al. (2003) randomly sampled speech-language pathologists at the 2000 ASHA Convention and found that $72 \%$ of participants indicated that their own competence with AAC systems was fair to poor. The same study found that $63 \%$ of participants reported poor to limited levels of comfort using an AAC system. Participants in this survey shared their opinions on education in AAC, including "colleges and universities need to expose us to more AAC system information" and "I do not feel I am ready to be responsible to implement an AAC program for a child" (p.6).

Gorenflo and Gorenflo (1990) surveyed members of the Michigan Speech-Language-Hearing Association and found that approximately two-thirds (66\%) of speech-language pathologists reported feeling as if they required additional knowledge in AAC. Similarly, a study cited by Ratcliff, Koul, and Llyod (2008) surveyed speech-language pathologists throughout the state of Michigan and found that approximately one-third of speech-language pathologists believe that their lack of AAC knowledge was a primary barrier to successful service delivery in AAC.

From this information, it is evident that many speech-language pathologists do not feel that they possess the competencies, knowledge, and skills in AAC to provide effective services to individuals with complex communication needs. Without appropriate competencies in AAC assessment and intervention, individuals with complex communication needs are more susceptible to poor communicative, academic, and social outcomes (Light \& McNaughton, 2014). Binger et al. (2012) suggested that at least part of the remedy to this situation is to ensure that students in preservice training programs receive the necessary training in AAC to feel confident about their ability to acquire and utilize AAC knowledge and skills in their careers. According to Costigan and Light (2010), these low levels of AAC knowledge and competence likely arise, at least in part, from inadequate preservice education in AAC.

Graduate programs that provide preservice education to future speech-language pathologists hold a responsibility to appropriately prepare their students for clinical service to individuals with complex communication needs. However, the current literature on preservice education and training in AAC indicates that many practicing professionals do not feel that their preservice education or graduate 
programs adequately prepared them to meet their clinical needs in AAC (Marvin et al., 2003; Gorenflo \& Gorenflo, 1990; Simpson, Beukelman, \& Bird, 1998; Ratcliff, Koul, \& Llyod, 2008; Costigan \& Light, 2010).

\section{Perspectives of Speech-Language Pathologists}

Competence. Costigan \& Light (2010) note that many speech-language pathologists are likely to graduate from their preservice training programs with unacceptably low levels of knowledge and skills in AAC, especially given the likelihood of serving individuals who use or could benefit from AAC in their clinical and educational practices. More than $54 \%$ of practicing speech-language pathologists responding to a survey conducted by Marvin et al. (2003) indicated that they would recommend AAC systems to their clientele; despite the fact that more than two-thirds of these same speech-language pathologists reported inadequate education and training to ensure an ethical level of practice to recommend the best fit AAC system for an individual client. This statistic leads to the assumption that at least some practicing speechlanguage pathologists may not be adhering to ASHA's Code of Ethics (2016) because they are practicing in an area in which they are not competent.

Preservice education. In a study conducted by Marvin et al. (2003), 71 practicing speechlanguage pathologists were surveyed regarding their perceptions of their training and experience using AAC. In this survey, $78 \%$ of respondents indicated that the level of education they received in AAC was not adequate to meet their clinical needs. In this same study, $80 \%$ of respondents reported that their preservice education in $\mathrm{AAC}$ was limited to poor, and $66 \%$ of respondents reported that their preservice training in AAC was fair to poor. Regardless of work setting or the number of years of experience, many respondents to this survey indicated a strong desire for more extensive preservice preparation in AAC.

To examine the current climate of preservice education in AAC, several studies have been conducted to examine and analyze coursework, clinical preparation, faculty expertise, and graduate student preparedness in AAC. These analyses aid professionals in gaining a better understanding of the 
progression of preservice education in $\mathrm{AAC}$, as well as current and recent status quo of preservice education programs.

\section{Preservice Education in AAC}

Coursework in AAC. In 1994, Koul and Llyod surveyed preservice education programs in speech-language pathology and found that $62 \%$ of the 131 responding programs provided a dedicated course in AAC. In a follow-up study in 2008, Ratcliff, Koul, and Llyod found that $73 \%$ of the 168 responding graduate programs provided at least one dedicated course in AAC. In these cases, a "dedicated course" was a course that has a primary focus in AAC. In addition to the increase in the number of preservice education programs that offer a dedicated course in AAC, the field has also observed an increase in the number of courses offered in AAC.

In 1994, Koul and Lloyd found that $23 \%$ of the 131 graduate programs in speech-language pathology offered two or more courses in AAC. A variety of studies have found that $80-100 \%$ of graduate programs in speech-language pathology who did not offer a dedicated course in AAC infused AAC content into other courses (Costigan \& Light, 2010; Ratcliff, Koul, \& Llyod, 2008, Koul \& Llyod, 1994). Koul and Lloyd (1994) found that $47 \%$ of the 131 responding preservice programs that infused AAC content into non-dedicated courses covered 1-3 hours of AAC content in the course, $22 \%$ of programs ( $n=37$ of 169) dedicated 4-6 hours of AAC content in the course, and less than $1 \%$ of programs dedicated 7 or more hours of non-dedicated course time to AAC content. However, the number of programs that spent dedicated hours on AAC content in non-dedicated courses showed an increase in 2008. Ratcliff, Koul, and Lloyd (2008) found that $48 \%$ of the 168 responding graduate programs who did not offer a dedicated course in AAC spent between 1-3 hours of class time on AAC content, and 11\% of responding graduate programs spent more than 6 hours infusing AAC content into non-dedicated courses. Finally, Costigan \& Light (2010) found that $81-93 \%$ of practicing speech-language pathologists reported that they did not complete a single course in their graduate program that focused on the needs of children with complex communication needs. 
AAC Course Content. Studies reveal that content in both dedicated and non-dedicated AAC courses typically consisted of introductory content, with between $15-53 \%$ of programs with dedicated AAC courses addressing AAC technology and operational skills (Costigan \& Light, 2010; Koul \& Llyod, 1994). Less than $10 \%$ of the 131 programs surveyed by Koul and Lloyd (1994) offered courses that were specific to AAC assessment, AAC intervention, or management of AAC. Ratcliff and Beukelman (1995) found that $67 \%$ of the 119 programs that offered coursework in AAC provided hands-on time with AAC equipment, $33 \%$ of programs required students to demonstrate operational competency with AAC equipment, and $82 \%$ of programs with $\mathrm{AAC}$ coursework involved the instructor demonstrating the use of AAC equipment to students. Similarly, in 2008, Ratcliff, Koul, and Lloyd found that $53 \%$ of the 168 responding speech-language pathology graduate programs who offered a dedicated course in AAC also provided laboratory instruction in AAC as a component of the course content. This typically focused on requiring students to demonstrate specific operational competencies with AAC technology. Ratcliff and Beukelman (1995) found that $70 \%$ of the 119 responding graduate programs in speech-language pathology indicated that hands-on activities with AAC equipment comprised less than $25 \%$ of the class time. This lack of hands-on practice with AAC equipment may inhibit speech-language pathologists' knowledge of AAC systems and their associated functions and features, thereby affecting their overall competencies and comfort in using and programming a variety of AAC systems.

Clinical Experiences in AAC. In addition to coursework in AAC, studies have examined the role of clinical or field work experiences in AAC at the preservice education level. In 1995, Ratcliff and Beukelman found that only an average $28 \%$ of the students in speech-language pathology graduate from the 119 programs that reported this data received any clinical clock hours in AAC. Similarly, in 2008, Ratcliff, Koul, and Lloyd found that $47 \%$ of the 168 responding graduate programs in speech-language pathology indicated that less than $25 \%$ of their students obtain any clinical clock hours in AAC. Therefore, at the time of these surveys, between $75-80 \%$ of students in these graduate programs in speech-language pathology received no clinical practicum experiences in AAC. 
Faculty Expertise in AAC. Despite the increase in the number of programs offering a dedicated course in AAC, the literature indicates that the faculty members who are teaching these courses may have limited expertise in AAC. In 2008, Ratcliff, Koul, and Lloyd found that 54\% of the 168 responding speech-language pathology graduate programs indicated that their teaching staff had minimal to no expertise in AAC. In a literature review done by Costigan and Light (2010), the authors reported that 54$71 \%$ of the graduate programs surveyed in previous studies failed to employ a faculty member with significant expertise in AAC or assistive technology.

Prior to 2014, graduate programs were required to fulfill education requirements in “communication modalities," a broad category that encompasses "oral, manual augmentative, and alternative communication techniques and assistive technologies" (ASHA, 2012). During this time frame, approximately half of graduate programs did not require their graduate students take any coursework in AAC to graduate (Costigan \& Light, 2010; Ratcliff, Koul, \& Llyod, 2008; Ratcliff \& Beukelman, 1995). This is likely because ASHA did not require specific education in AAC to meet the certification standards for the Certificate of Clinical Competence. The combined lack of compulsory coursework and clinical experiences in AAC left many speech-language pathology students to graduate from preservice programs with minimal to no exposure in AAC (Costigan \& Light, 2010).

Ratcliff and Beukelman reported in 1995, that of the 119 programs responding to their survey, only $42 \%$ of their graduating students would be able to provide services to AAC clients on their caseload, with the caveat that some of these students would be minimally prepared and would need additional supervision and in-service training to become competent in AAC service provision. In 2008, nearly half (46\%) of the 168 responding speech-language pathology programs indicated that less than 1 in 4 of their students were prepared to work with clients with AAC needs upon graduating from their program, and $67 \%$ indicated that none or only some of their graduating students were prepared to work with clients who used AAC. 
However, in 2014, ASHA changed the former "communication modalities" requirement to specified compulsory education and/or training in AAC (ASHA, 2014; ASHA, 2012). Thus, graduate programs in speech-language pathology are now required to provide opportunities for students to gain explicit knowledge and skills in the area of AAC to be eligible to receive the Certificate of Clinical Competence. It is possible that with this change in terminology and expectations, graduate programs may have increased the number and frequency of coursework and clinical experiences to knowledge and skills in $\mathrm{AAC}$.

\section{Trends in Preservice Education in AAC}

Through comparison of studies in preservice education in AAC across time, it is evident that there has been some increase in the prevalence and quantity of preservice AAC education opportunities. Ratcliff, Koul, \& Llyod (2008) found that responding speech-language pathology programs were offering 41 more courses in AAC than were reported in 1994, and 24 more courses in AAC than were reported in 1995. Similarly, Costigan \& Light (2010) found that the percentage of graduate programs in speechlanguage pathology that offered AAC courses increased from 62\% to 73\% between 1994 and 2008. Although this trend in preservice education in AAC is positive, there is still a need for additional preservice education opportunities in AAC. Light et al. (2012) note that inadequate preservice preparation in AAC at the graduate level leaves many current graduates ill-prepared to meet the needs of individuals with complex communication needs. Preservice education in AAC is vital to the future success of individuals with complex communication needs. Cumley and Beukelman (1992) state that as instruction to professionals becomes more effective, their facilitation of communication should result in improvements in the communication competencies of AAC users. These improved competencies lead to better opportunities for persons who use AAC to be successful communicators in a variety of communicative contexts. Thus, improvement in the climate of preservice education in AAC is crucial to ensuring the success of clients who use AAC. 
Given the growing number of individuals with complex communication needs who use or could benefit from the use of AAC systems, it is critical that speech-language pathologists have the necessary knowledge and skills in AAC to provide clinically competent services in AAC. The current literature on preservice education programs in AAC indicates that insufficient education and training has been provided to graduate students in AAC. However, given this information, and the recent change in preservice education requirements from "communication modalities" to specifically state required education and preparation in "augmentative and alternative communication," (ASHA, 2014; ASHA, 2012) it is necessary to reevaluate preservice education in AAC provided in graduate programs in speechlanguage pathology to define and describe the current climate of preservice education in AAC.

\section{Purpose}

The purpose of this research was to describe the types and frequencies of educational and clinical preparation in AAC provided to graduate students in speech-language pathology programs accredited by the Council on Academic Accreditation (CAA). Specifically, this study is intended to provide up-to-date information about the characteristics and practices in speech-language pathology graduate programs in the area of AAC, including information about coursework and clinical experiences in AAC, faculty members' expertise in AAC, and AAC technologies used by graduate programs. 


\section{CHAPTER II}

\section{Method}

This research explored the types and frequencies of preservice coursework and clinical preparation in AAC for graduate students in speech-language pathology. The survey was sent via Qualtrics email to program directors, chair persons, clinic directors, professors, and faculty members of the 251 graduate programs in speech-language pathology across the United States and Puerto Rico accredited by the Council on Academic Accreditation (CAA).

\section{Participants}

The participants in the study were 85 responding program directors, chair persons, or faculty members of accredited graduate programs in speech-language pathology. Demographic information obtained through the survey included: a) the participant's position within their graduate program in speech-language pathology, b) the state in which their graduate program is located, for how many years said graduate program has been accredited, c) how many faculty members are employed by said graduate program, and d) the average number of students enrolled in said graduate program.

\section{Survey}

This survey was developed using Qualtrics software. After developing the survey, it was piloted by two adjunct faculty members at Maryville University in St. Louis, Missouri. The investigator received the completed pilot surveys and associated feedback and revised the layout of the survey and the wording of some survey questions.

The survey entitled "Preservice Education in AAC: An Update" was a fifty-three-item online questionnaire that was designed to gather information about the current preparation education in AAC in graduate programs in speech-language pathology. The survey included five sections: demographics, 
coursework in AAC, clinical experiences in AAC, faculty members, and supplemental or additional fieldwork experiences for graduate students in AAC.

The first section sought to gather demographic information about graduate programs in speechlanguage pathology, including the relative size of their program in regard to number of graduate students enrolled in the program, the number of faculty members employed in the graduate program, for how many years the graduate program had been accredited by the CAA, and the state in which the graduate program was located.

The second section obtained information regarding coursework in AAC available to graduate students in speech-language pathology, including information on dedicated vs non-dedicated coursework, the content included in coursework in AAC, hands-on experiences with AAC systems embedded into coursework, and barriers to providing comprehensive coursework in AAC.

The third section acquired information regarding clinical and field work experiences provided to graduate students in speech-language pathology. This section gathered information related to: clinical clock hours in AAC, required hands-on activities with AAC technology, types of AAC systems that students had access to, and the population(s) of individuals who use AAC that graduate students work with in their clinical practica and field work experiences.

The fourth section of the survey gained information about faculty members employed by the graduate program, including their relative levels of expertise with AAC. The fifth and final section of the survey gathered information regarding additional or supplemental field work experiences in AAC, such as training grants or personnel preparation programs. The survey used a variety of question types (multiple choice questions, yes or no questions, multiple selection, and text boxes) to obtain the desired information. The entire survey is located in Appendix 1. 


\section{Procedure}

The investigator utilized the American Speech-Language-Hearing Association's Ed Find website to obtain lists and contact information of CAA accredited graduate programs in speech-language pathology. Once contact information was obtained for each of the 251 accredited graduate programs, the researcher solicited participation by emailing: a) a link to the survey, b) a short information statement about the survey and research study, and c) an outline of expectations and procedures to the program's department chair, program director, or clinical director. The link embedded in the email directed participants to the research survey, which was hosted via The University of Kansas' connection to Qualtrics software (https://kusurvey.ca1.qualtrics.com). The recipient of the email was asked to pass the survey along to another faculty member if they felt that there was someone that was better suited to answer the survey questions. The participants were not asked to provide their names or other personal information in the survey. However, participants were given an option to include the name and contact information of faculty member in their graduate program for the investigator to contact with follow-up questions. For the participants who did not provide this information, the identity of the participants remained confidential. If participants did choose to provide their contact information for follow-up questions, the investigator kept this data within Qualtrics for future follow-up questions.

Study participants were sent an initial email containing the study's information statement and a link to complete the survey, participants who did not complete their survey response were sent four email reminders over the course of three months. Initial invitations were sent on November 29, 2017. Reminder emails were sent on January 3, 2018; January 18, 2018; February 5, 2018; and February 22, 2018. Following the fourth reminder, only 61 surveys had been completed. At this time, the investigator utilized an online randomizer tool to aid in selection of 100 numbers between 1-251. Each number correlated with a graduate program, organized from 1-251 in alphabetical order (e.g., the number "1" corresponded with Abilene Christian University). The investigator called each of the 100 randomized graduate programs to follow-up on survey participation. Following these phone calls, an additional 24 programs completed the 
survey, totaling in 85 respondents. However, it is important to note that participants were not forced to respond to a question before moving to the next question. Therefore, not all participants answered each question. It should be assumed that percentages and totals have been calculated based upon the total number of participants who answered that question, not the total number of participants who completed the survey in its entirety. 


\section{CHAPTER III}

\section{Results}

This study evaluated the current climate and characteristics of preservice education in AAC provided in graduate programs in speech-language pathology. Participation in this research involved the completion of an online survey by an employee or faculty member affiliated with an accredited graduate program in speech-language pathology. Data representing participants' survey responses will be presented. A total of 85 participants completed the survey for a response rate of approximately $34 \%$. Although 85 participants completed the survey, not all participants answered every question presented. Participants had the option to skip a question without answering it or leave an answer blank and continue to the remaining survey questions without penalty. Participants were much more likely to respond to multiple choice style questions than free response style questions (questions that required the participant to generate and type a response to the question). The survey included five sections: a) demographics, b) coursework in AAC, c) clinical experiences in AAC, d) faculty members, and e) additional learning opportunities in AAC.

\section{Demographic Information}

The first section of this survey sought to gather demographic information about graduate programs in speech-language pathology, including the relative size of their program in regards to number of graduate students enrolled in the program, the number of faculty members employed in the graduate program, for how many years the graduate program has been accredited by the CAA, and the state in which the graduate program was located. Data is outlined and discussed below.

The participants in the study reported their position within their associated graduate program. Table 2 presents this information. 
Table 2

Participants' Position within Their Graduate Program

Position within Graduate Program

Number of Participants

\begin{tabular}{lr}
\hline Department Chair & 26 \\
\hline Program Director & 14 \\
\hline Academic Faculty Member & 20 \\
\hline Clinical Faculty Member & 12 \\
\hline Staff Member & 0 \\
\hline Other: Please Specify & 9
\end{tabular}

Participants who selected "other" were asked to indicate their position within the graduate program in a free response text box. These responses revealed that the nine participants who selected "other" were comprised of six directors of clinical education or clinic directors, one individual who is both a department chair and program director, one adjunct faculty member, and one speech pathologist affiliated with an off-site clinic associated with the university.

Surveys were sent to faculty members of graduate programs in speech-language pathology in 48 states, Washington D.C., and Puerto Rico. Alaska and Delaware were excluded, as CAA accredited graduate programs in speech-language pathology do not currently exist in those states. Regional data associated with the participants' universities is presented in Table 3. 
Table 3

Participants' Program Region in the United States

\begin{tabular}{clc} 
Region & \multicolumn{1}{c}{ States in the Region } & $\begin{array}{c}\text { Number of } \\
\text { Participants }\end{array}$ \\
\hline \multirow{2}{*}{ Midwest } & $\begin{array}{l}\text { Illinois, Indiana, Iowa, Kansas, Michigan, Minnesota, Missouri, } \\
\text { Nebraska, North Dakota, Ohio, South Dakota, and Wisconsin }\end{array}$ & 20 \\
\hline \multirow{2}{*}{ Northeast } & $\begin{array}{l}\text { Connecticut, Delaware, Maine, Maryland, Massachusetts, New } \\
\text { Hampshire, New Jersey, New York, Pennsylvania, Rhode Island, }\end{array}$ & \\
& Vermont, and Washington D.C. & 27 \\
\hline South & $\begin{array}{l}\text { Alabama, Arkansas, Florida, Georgia, Kentucky, Louisiana, } \\
\text { Maryland, Mississippi, North Carolina, Oklahoma, Puerto Rico, } \\
\\
\text { South Carolina, Tennessee, Texas, Virginia, and West Virginia }\end{array}$ & \\
\hline West & Arizona, California, Colorado, Hawaii, Idaho, Montana, Nevada, \\
& New Mexico, Oregon, Utah, Washington, and Wyoming
\end{tabular}

Participants were asked questions regarding the size of their graduate program, in relation to the number of students enrolled in the program and the number of faculty members employed by the program. Eleven participants noted that they had 15-29 total students enrolled in their program, 16 participants noted that they had 30-44 total students enrolled in their program, 13 participants revealed that they had 45-59 total students enrolled in their program, and 40 participants stated that their graduate program had more than 60 total students enrolled in their program. Similarly, to gather additional information about the size of each graduate program, participants were asked to indicate the number of total faculty members employed by their graduate program. One participant stated that their graduate program employed 3-5 faculty members, eleven participants stated that their graduate program employed 6-9 faculty members, 28 participants stated that their graduate program employed 10-14 faculty members, and 40 participants noted that their graduate program employed more than 15 faculty members.

\section{Coursework in AAC}

The second section of the survey obtained information regarding coursework in AAC available to graduate students in speech-language pathology, including information on dedicated vs non-dedicated 
coursework, the content included in coursework in AAC, hands-on experiences with AAC systems embedded into coursework, and barriers to providing comprehensive coursework in AAC.

Ninety-six percent of respondents indicated that their graduate program offered some type of coursework in AAC, and ninety-six percent of the respondents who reported that their graduate program had coursework in AAC also noted that their graduate program offered a dedicated course in AAC. For the purposes of this study, a "dedicated course in AAC" was defined to participants as "a course with a primary focus in AAC." Participants were asked to indicate the number of dedicated courses that their graduate program offered. Eighty-four percent of this group of respondents stated that their graduate program offered one dedicated course in AAC, while the remaining $16 \%$ noted that their graduate program offered two or more dedicated courses in AAC.

Likewise, eighty-six percent of respondents indicated that their graduate program required its students to complete a course in AAC. Eighty-nine percent of respondents stated that $76-100 \%$ of students who graduate from their program have taken a dedicated course in AAC, whereas $4 \%$ of respondents stated that $51-75 \%$ of students who graduate have taken a dedicated course in AAC, an additional $4 \%$ stated that $26-50 \%$ of students who graduate have taken a dedicated course in AAC, and $3 \%$ of the participants stated that $0-25 \%$ of students who graduate have taken a dedicated course in AAC.

For graduate programs who did not offer dedicated coursework in AAC, participants were asked about alternative learning opportunities for students to gain knowledge and skills in AAC. Thirty-eight percent of participants indicated that students in their graduate program gained knowledge and skills in AAC primarily through clinical experiences. An additional 38\% indicated that their graduate students primarily gained knowledge and skills in AAC through content infusion in non-dedicated courses. Less than one percent of participants indicated that their graduate students primarily gained knowledge and skills in AAC through continuing education units (CEUs). 
Participants were asked to answer questions regarding the infusion of AAC content into nondedicated coursework. For the purposes of this study, a "non-dedicated course in AAC" was defined to participants as "a course that includes AAC content but does not have a primary focus in AAC." Seventynine percent of respondents indicated that their graduate program infused AAC content into nondedicated courses. However, the majority of participants (52\%) revealed that less than three hours of classroom time was devoted to AAC in non-dedicated courses. The amount of time devoted to AAC in non-dedicated courses is presented in Table 4.

Table 4

Amount of Classroom Time Devoted to AAC Content in Non-Dedicated Coursework

Amount of Classroom Time Devoted to AAC Number of Graduate Programs

\begin{tabular}{lc}
\hline Approximately 1 hour of classroom time & 20 \\
\hline Approximately 2 hours of classroom time & 17 \\
\hline Approximately 3 hours of classroom time & 14 \\
\hline Approximately 4-6 hours of classroom time & 7 \\
\hline More than 7 hours of classroom time & 4
\end{tabular}

Participants were asked to approximate the percentage of students who graduate from their program who have taken a non-dedicated course in AAC. Fifty-six participants indicated that 76-100\% of students who graduate from their program have taken a non-dedicated course in AAC, whereas one participant indicated that $51-75 \%$ of students who graduate from their program have taken a nondedicated course in AAC, one participant indicated that $26-50 \%$ of students who graduate from their program have taken a non-dedicated course in AAC, and fifteen participants indicated that $0-25 \%$ of students who graduate from their program take a non-dedicated course in AAC. 
More than $97 \%$ of respondents stated that their program's coursework in AAC included content on AAC assessment. Participants were given the option to complete a free response question to provide additional information about specific topics and themes discussed in coursework. Major themes and topics regarding AAC assessment that emerged include: a) overall assessment principles and procedures, b) The Participation Model, c) assessment of individuals with developmental disabilities/pediatric populations , d) assessment of individuals with acquired disabilities/adult populations, e) assessment of the client's specific capabilities (e.g., language, cognition, motor, etc.), f) feature matching, and g) device features and symbol sets.

Similarly, $100 \%$ of participants noted that their program's coursework in AAC included content on AAC interventions. Participants had the choice to complete a free response question to provide additional information about specific topics and themes discussed in the coursework. Major themes and topics regarding AAC intervention that emerged include: a) overall AAC intervention principles, b) treatment of individuals with specific diagnoses, c) treatment strategies, d) training communication partners, and e) language development.

In addition to questions regarding course content, participants were asked to provide information about the types of hands-on experiences with AAC systems that students engaged in as part of their coursework in AAC. Ninety-three percent of respondents stated that their coursework included opportunities for students to complete hands-on experiences with AAC systems. Respondents were given the opportunity to complete a free response question to provide additional information about the types of hands-on experiences with AAC systems that their graduate programs offered. Major themes that emerged included: a) hands-on practice with dedicated devices, b) hands-on practice with low-tech devices, c) hands-on practice with iPad applications, d) classroom visits from local AAC vendor representatives.

In the final question of this section of the survey, participants were asked to identify barriers that their graduate program faced in providing comprehensive coursework in AAC. Participants could select 
more than one answer from the provided list, as well as utilize a free-response box to discuss barriers more specifically. Table 5 presents the barriers to providing comprehensive coursework in AAC.

\section{Table 5}

Barriers to Providing Comprehensive Coursework in AAC

Barriers Number of Participants

\begin{tabular}{lr}
\hline Access to AAC systems or devices & 26 \\
\hline Student's coursework schedules & 21 \\
\hline Faculty members with limited expertise in AAC & 20 \\
\hline Funding & 14 \\
\hline Other & 23
\end{tabular}

The respondents who indicated that "other" factors were barriers to providing comprehensive coursework in AAC were given the option to complete a free response question to discuss specific barriers that their graduate program faces in providing comprehensive coursework in AAC. Major themes that emerged from this free response question included: a) difficulty meeting all of ASHA's criteria for clinical certifications (Big Nine) and competition with other offered coursework, and b) no barriers are present that impact the ability to provide comprehensive coursework in AAC.

\section{Clinical Experiences in AAC}

The third section of the survey acquired information regarding clinical and field work experiences provided to graduate students in speech-language pathology. This section gathered information related to: clinical clock hours in AAC, required hands-on activities with AAC technology, types of AAC systems that students had access to, and the population(s) of individuals who use AAC that graduate students work with in their clinical practica and field work experiences. 
Ninety-six percent of respondents indicated that their graduate program provided clinical or hands-on experiences for students to learn about AAC. Participants were encouraged to select the types of hands-on experiences and learning opportunities that were provided to students. Table 6 presents the types of hands-on experiences provided to students.

Table 6

Types of Hands-On Experiences in AAC Provided to Students in Their AAC Coursework

Clinical/Hands-On Experience Number of

\begin{tabular}{l} 
Participants \\
\hline
\end{tabular}

\begin{tabular}{lc}
\hline Students observe instructor demonstrate activities and/or technology & 43 \\
\hline Students get hands-on experience, but no requirements for operational competency of & 39 \\
AAC systems & 35 \\
\hline $\begin{array}{l}\text { Students are required to demonstrate specific operational competencies of AAC } \\
\text { technology }\end{array}$ & 9 \\
\hline Other & 0
\end{tabular}

Participants who selected "other" hands-on experiences were provided to students to learn about AAC were encouraged to complete a free-response question to discuss specific opportunities that their graduate program provides. Major themes that emerged from this free-response question included: a) clinical practicum opportunities, and b) AAC/AT seminars.

Sixty-four percent of participants noted that their graduate program offered clinical experiences in AAC services to multicultural populations, often attributing this to the diverse populations surrounding their university. Participants were asked about the settings in which graduate students participated in clinical experiences in AAC. This question allowed participants to select more than one setting. Table 7 presents the settings that graduate students completed clinical experiences in AAC. 
Table 7

Settings of Clinical Experiences in AAC

Clinical Experience Settings

Number of Participants

\begin{tabular}{lr}
\hline University Clinic & 65 \\
\hline School & 59 \\
\hline Rehabilitation Setting & 49 \\
\hline Outpatient Hospital & 48 \\
\hline Inpatient Hospital & 43 \\
\hline Skilled Nursing Facility & 39 \\
\hline Community Clinic & 27 \\
\hline Private Practice & 26 \\
\hline Home Health Care & 14
\end{tabular}

Participants were asked to describe the populations of individuals who used AAC that their graduate students worked with in clinical experiences. This question allowed participants to select more than one population. Table 8 presents the populations of individuals who use AAC that graduate students worked with in clinical experiences.

Table 8

Populations of Individuals That Use AAC Population Number of Participants

\begin{tabular}{lr}
\hline Pediatrics with Developmental Disabilities & 70 \\
\hline Adults with Acquired Disabilities & 66 \\
\hline Adults with Developmental Disabilities & 59 \\
\hline Geriatrics with Acquired Disabilities & 55 \\
\hline Pediatrics with Acquired Disabilities & 46 \\
\hline Geriatrics with Developmental Disabilities & 28
\end{tabular}


Eighty-eight percent of respondents stated that their graduate program possessed AAC systems to be used for clinical and coursework experiences. Respondents reported a range of AAC systems that their graduate program possessed, including a variety of high-tech, mid-tech, and low-tech devices. Examples included: a) TobiiDynavox T-series, b) TobiiDynavox I-series, c) iPad applications (e.g., Prooquo2go, Go Talk, LAMP Words for Life), d) Saltillo's NovaChat, e) TobiiDynavox Indi, f) various PRC devices, and g) various low-tech devices (e.g., PODD and PECS). Some respondents indicated that their graduate program also possessed alternative access methods, like a BigMac switch and NuEye Eye Gaze software, although alternative access technology was not specifically evaluated. Graduate programs that did not have their own AAC systems were asked to indicate the process by which their graduate program acquired AAC systems to be used for clinical and coursework opportunities. A free-response question revealed that long-term loans from local agencies and/or device representatives was the primary form of device acquisition.

Respondents whose graduate programs did not possess AAC systems were asked to describe the challenges they faced in acquiring AAC systems for their university. Overwhelmingly, participants cited funding and financial burdens as the primary barrier to obtaining AAC systems. Participants also cited the rapid rate of technology changes and fears of devices become obsolete as a challenge to obtaining AAC systems for their graduate program.

Participants were asked to reveal the percentage of graduate students who leave their graduate program who have earned clinical clock hours in AAC. Table 9 presents this data. 
Table 9

Percentage of Students That Graduate with Clinical Clock Hours in AAC

Percentage of Students that Have Earned Clinical Clock Hours in AAC Number of Participants

\begin{tabular}{lr}
\hline $0-25 \%$ of students & 8 \\
\hline $26-50 \%$ of students & 18 \\
\hline $51-75 \%$ of students & 17 \\
\hline $76-100 \%$ of students & 27
\end{tabular}

To evaluate the number of graduate students who graduated with some preparation to work with individuals who use and need AAC, participants were asked to approximate the percentage of students who leave their program with knowledge and skills in AAC. For the purposes of this study, knowledge and skills in AAC was defined to participants as "assessment, documentation, development and intervention of AAC, evaluation of AAC outcomes and effectiveness, advocacy, and coordination of AAC services." Table 10 presents these percentages below.

Table 10

Percentage of Students That Graduate with Knowledge and Skills in AAC

Percentage of Students Who Have Acquired Knowledge and Skills in AAC Number of Participants

$\begin{array}{ll}0-25 \% \text { of students } & 0\end{array}$

$\begin{array}{ll}26-50 \% \text { of students } & 7\end{array}$

\begin{tabular}{lc}
\hline $51-75 \%$ of students & 8
\end{tabular}

$\begin{array}{lc}76-100 \% \text { of students } & 54\end{array}$

To describe the relationship between the percentage of students who graduated from a program with earned clinical clock hours in AAC and a program's on-site AAC systems available for coursework and clinical opportunities, a cross-comparison tabulation was done. Table 11 presents this information. 
Table 11

Comparison of Students That Graduate with Clock Hours in AAC and the Presence of On-Site AAC Systems/Devices

Graduate Program Possession of AAC Systems

\begin{tabular}{c|lccc}
\hline Percentage of & & Yes & No & Total \\
Graduate Students & $0-25 \%$ & 7 & 1 & 8 \\
\cline { 2 - 5 } Who Acquire & $26-50 \%$ & 14 & 3 & 18 \\
Clinical Clock & $51-75 \%$ & 16 & 1 & 17 \\
\cline { 2 - 5 } Hours in AAC & $76-100 \%$ & 26 & 1 & 27 \\
\hline & & & & 70
\end{tabular}

In a free- response question, participants were asked to describe the barriers to providing clinical experiences in AAC to its graduate students. Major themes that emerged from this question included: a) the low-incidence of individuals who use AAC in their clinical settings, b) varied experiences in AAC provided in externships, and c) varied experiences in AAC provided during clinical practica. In general, respondents noted that graduate students are not guaranteed a clinical placement that provides access to learning opportunities in AAC, and this is a barrier to ensuring that all students in a graduate program gain access to clinical experiences in AAC.

Participants were asked to indicate the percentage of its graduate students that acquired knowledge and skills in AAC throughout their graduate program. For the purposes of this survey, "knowledge and skills in AAC" was defined to participants as "assessment, documentation, development and intervention of AAC, evaluation of AAC outcomes and effectiveness, advocacy, and coordination of AAC services." Ten percent of respondents stated that 26-50\% of graduate students acquired knowledge and skills in AAC, twelve percent of respondents stated that $51-75 \%$ of graduate students acquired knowledge and skills in AAC, and seventy-eight percent of respondents stated that 76-100\% of their 
graduate students acquired knowledge and skills in AAC. Participants were not explicitly asked to reveal the manner in which graduate students acquired knowledge and skills in AAC, nor were they asked to describe the depth of knowledge and skills that their students acquire. When asked to indicate which knowledge and skills in AAC were most difficult for graduate students to learn, forty-three percent of respondents reported that their graduate students had the most difficulty acquiring knowledge and skills in the area AAC assessment. Fifteen percent of respondents indicated that their graduate students had the most difficulty acquiring knowledge and skills in the area of AAC intervention. The remaining $42 \%$ of respondents stated that their graduate students had the most difficulty acquiring knowledge in skills in both AAC assessment and intervention.

Participants were asked to describe the greatest barriers that their graduate program faced in providing comprehensive clinical experiences in AAC. Table 12 presents their responses.

Table 12

Barriers to Providing Comprehensive Clinical Experiences in AAC

Barriers to Provision of Clinical Experiences in AAC Number of Participants

\begin{tabular}{ll}
\hline Access to Clients Who Use AAC & 39
\end{tabular}

\begin{tabular}{ll}
\hline Funding & 25 \\
\hline
\end{tabular}

Access to AAC Systems or Devices 24

Faculty Members with Limited Expertise in AAC 20

Other

Participants who selected "other" were encouraged to complete a free-response question to describe the types of barriers that their graduate program faces in providing comprehensive clinical experiences in AAC to its students. Respondents cited a variety of barriers that their graduate program faced, including: a) limited number of clinical placements that provide opportunities for students to work with AAC, b) the short-term nature of clinical practicums, which makes it difficult for students to see AAC assessment/treatment beyond one semester, and c) student schedules and limited time. 


\section{Faculty Members}

The fourth section of the survey gained information about faculty members employed by the graduate program, including their relative levels of expertise with AAC. Questions in this section were not intended to evaluate the competencies and expertise of the faculty members completing the survey, but rather these questions were designed to gather objective information about the AAC expertise of all faculty members employed by their graduate program.

Participants were asked to indicate the individuals who were responsible for teaching coursework in AAC, using a multiple-choice format with the option to select multiple categories. Participants were instructed to select all categories that applied. Of the 152 total answers to this question, 135 (89\%) included an individual with some level of experience in AAC was teaching coursework in AAC. Table 13 presents the individuals responsible for teaching coursework in AAC.

Table 13

Individuals Responsible for Teaching Coursework in AAC

Faculty Position Number of Participants

\begin{tabular}{lr}
\hline Faculty member with clinical experience in AAC & 65 \\
\hline Faculty member with research experience in AAC & 44 \\
\hline Adjunct faculty member with experience in AAC & 23 \\
\hline Faculty member without research experience in AAC & 9 \\
\hline Faculty member without clinical experience in AAC & 8 \\
\hline Doctoral student with experience in AAC & 3 \\
\hline Graduate teaching assistant & 2 \\
\hline Adjunct faculty member without experience in AAC & 0 \\
\hline Doctoral student without experience in AAC & 0
\end{tabular}


Academic Faculty Members. Participants were asked to describe the expertise levels of the academic/tenure-track faculty members in the area of AAC. Figure 1 presents the number of academic/tenure-track faculty members who had a primary expertise in AAC, secondary expertise in AAC, or limited expertise in AAC.

Figure 1

Academic/Tenure-Track Faculty Levels of Expertise in AAC

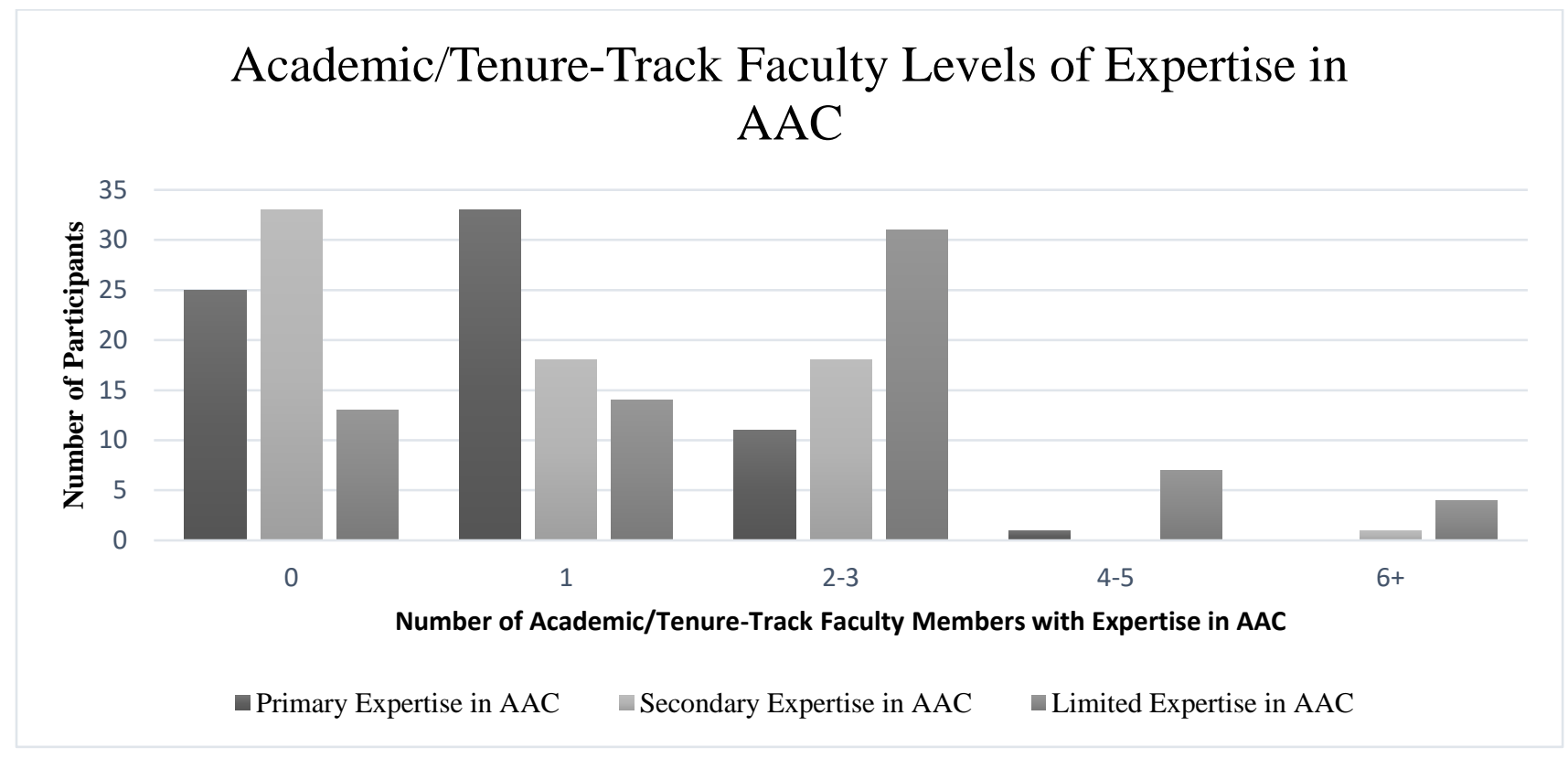

Clinical Faculty Members. Participants were asked to describe the expertise levels of the clinical faculty members in the area of AAC. Figure 2 presents the number of clinical faculty members who possess a primary expertise in AAC, secondary expertise in AAC, or limited expertise in AAC. 
Figure 2

Clinical Faculty Levels of Expertise in AAC

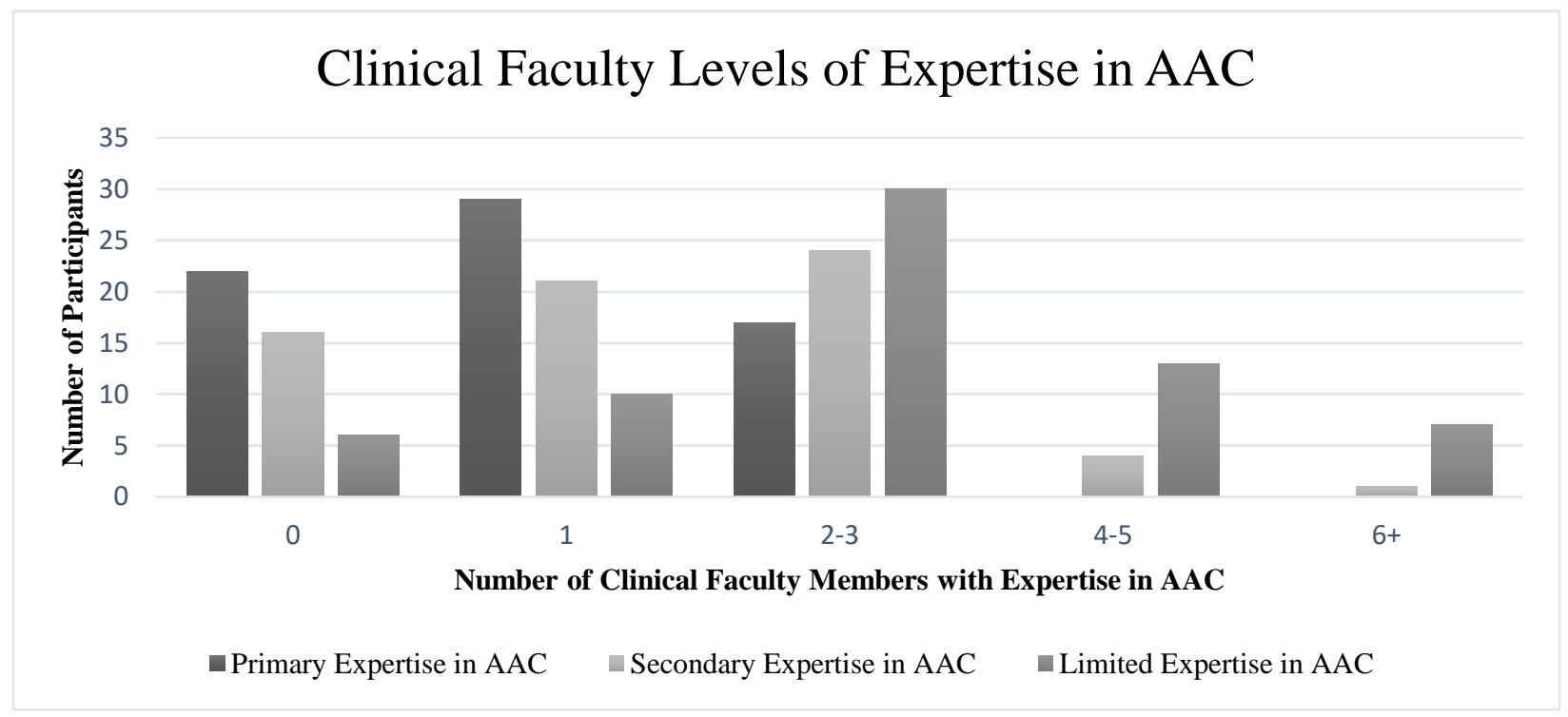

In order to describe the relationship between the number of total faculty members at a graduate program and the number of faculty members at that program with a primary expertise in AAC, a crosscomparison tabulation was done. The comparison table is presented in Table 15. 
Table 14

Comparison of Total Faculty Members and Faculty Members with Primary Expertise in AAC

\begin{tabular}{|c|c|c|c|c|c|c|}
\hline $\begin{array}{l}\text { Total Faculty } \\
\text { Members }\end{array}$ & & $3-5$ & $6-9$ & $10-14$ & $15+$ & Total \\
\hline \multirow{6}{*}{$\begin{array}{l}\text { Academic } \\
\text { Faculty with } \\
\text { Primary } \\
\text { Expertise in } \\
\text { AAC }\end{array}$} & 0 & 1 & 3 & 8 & 13 & 25 \\
\hline & 1 & 0 & 4 & 13 & 16 & 33 \\
\hline & $2-3$ & 0 & 2 & 1 & 8 & 11 \\
\hline & $4-5$ & 0 & 0 & 0 & 1 & 1 \\
\hline & $6+$ & 0 & 0 & 0 & 0 & 0 \\
\hline & Total & 1 & 9 & 22 & 38 & 70 \\
\hline \multirow{6}{*}{$\begin{array}{c}\text { Clinical } \\
\text { Faculty with } \\
\text { Primary } \\
\text { Expertise in } \\
\text { AAC }\end{array}$} & 0 & 0 & 2 & 8 & 12 & 22 \\
\hline & 1 & 0 & 3 & 11 & 15 & 29 \\
\hline & $2-3$ & 1 & 3 & 2 & 11 & 17 \\
\hline & $4-5$ & 0 & 0 & 0 & 0 & 0 \\
\hline & $6+$ & 0 & 0 & 0 & 0 & 0 \\
\hline & Total & 1 & 8 & 21 & 38 & 68 \\
\hline
\end{tabular}

This table illustrates a possible relationship between the number of total faculty members employed by a graduate program and the number of clinical and/or academic faculty members who possess a primary expertise in AAC. Graduate programs that reported higher numbers of total faculty members were more likely to have a faculty member with primary expertise in AAC.

\section{Additional Learning Opportunities in AAC}

The fifth and final section of the survey gathered information regarding additional or supplemental fieldwork or experiences in AAC, such as training grants or personnel preparation programs. Forty-seven percent of respondents reported that their graduate program offered additional experiences for graduate students to gain AAC experience in the field, outside of clinical practicum experiences. Sources of additional learning opportunities in AAC included: a) externship sites, b) conferences and seminars, c) service-learning projects, d) summer camps, and e) research experiences. 
Thirteen percent of participants stated that their graduate program had AAC training grants, and nineteen percent of participants stated that their graduate program previously had AAC training grants. For the purposes of this survey, "training grants" were defined to participants as "funding opportunities for students in the area of AAC."

Finally, participants were asked to describe the greatest barrier(s) to providing comprehensive preservice education in AAC to graduate students. Participants were able to select more than one response and were encouraged to complete a free-response question to describe these barriers in depth. Table 15 presents these barriers.

Table 15

Barriers to Providing Comprehensive Preservice Education in AAC

Barriers to the Provision of Comprehensive Preservice Education in AAC Number of Participants

\begin{tabular}{lc}
\hline Faculty Members with Limited Expertise in AAC & 36 \\
\hline Access to AAC Systems or Devices & 30 \\
\hline Limited Availability of Clinical Experiences/Opportunities in AAC & 26 \\
\hline Funding & 19 \\
\hline Other & 13
\end{tabular}

Respondents who selected "funding" or "other" for this question were encouraged to provide additional information in the free-response portion of this question. Respondents who selected "funding" as a barrier to providing comprehensive preservice education in AAC revealed a variety of explanations, including: a) lack of federal grants to purchase/update AAC devices, b) the cost of AAC devices, c) limitations in the university budget, d) inability to provide adequate salary to hire an AAC expert, and e) lack of federal grants to obtain training grants. Forty-two percent of participants who completed the freeresponse question indicated that their graduate program did not experience any barriers to providing comprehensive preservice education in AAC. The remaining respondents cited the following barriers: a) 
limited time of faculty members, b) coursework schedules, and c) limited clinical opportunities for students to gather clock hours in AAC. 


\section{CHAPTER IV}

\section{Discussion}

The purpose of this research was to describe the types and frequencies of educational and clinical preparation in AAC provided to graduate students in speech-language pathology programs accredited by the Council on Academic Accreditation (CAA). Specifically, this study was designed to gather up-to-date information about the characteristics and practices of speech-language pathology graduate programs in the area of AAC, including information about coursework and clinical experiences in AAC, faculty members' expertise in AAC, and AAC technologies used by graduate programs.

\section{Coursework in AAC}

Eighty-six percent of respondents reported that their graduate program required its students to complete a course in AAC. Ninety-six percent of respondents reported that their graduate program offered at least one dedicated course in AAC. This is an increase from 2008, when only $73 \%$ of the 168 responding programs offered at least one dedicated course in AAC. However, the number of dedicated courses offered by each graduate program in speech-language pathology has decreased. In 1994, Koul and Llyod reported that $23 \%$ of their responding 131 graduate programs offered two or more courses in AAC; whereas only $16 \%$ of respondents in this survey reported offering two or more dedicated courses in AAC. It is possible that this decrease in the number of dedicated courses in AAC offered by graduate programs could be due to an increase in other required coursework (e.g., coursework in other ASHA areas). Perhaps the number of offered dedicated courses in AAC has decreased to allow students to partake in additional or more intensive clinical practicum experiences. It is also possible that the decrease in the number of dedicated courses in AAC could be correlated with a lack of faculty members with expertise in AAC to teach the courses. Another possible factor related to the decrease could be attributed to the unique characteristics of the participants who chose to respond to this survey. Because the sample size of this survey is smaller than the sample size of Koul \& Lloyd's 1994 study, it is possible that this could have 
impacted the types of responses yielded from the survey, and participants who do offer coursework in AAC may have been more likely to respond to the survey.

Seventy-seven percent of respondents reported that that 76-100\% of students who graduate from their program have taken a non-dedicated course in AAC. Less than $1 \%$ of respondents reported that between $26-75 \%$ of students who graduate from their program have taken a non-dedicated course in AAC, $16 \%$ of respondents indicated that $0-25 \%$ of students who graduate from their program take a nondedicated course in AAC. These numbers suggest that more graduate students in speech-language pathology are completing dedicated coursework in AAC than non-dedicated coursework in AAC.

Ninety-three percent of respondents stated that their coursework included opportunities for students to complete hands-on experiences with AAC systems. Many reports included opportunities for students to have hands-on practice in using and programming high-tech and low-tech devices, as well as classroom visits from local AAC vendor representatives. This number has increased since 1995, when Ratcliff and Beukelman found that $67 \%$ of the 119 programs that offered coursework in AAC provided hands-on time with AAC equipment. This increase is likely due to an increased prevalence of the number of AAC systems and technologies on the market, as well as an increase in the population of individuals who use or could benefit from AAC. It is possible that many of these university clinics serve clients with complex communication needs, and therefore, would be more likely to possess on-site AAC systems for student use for clinical and coursework experiences. The increase in the number of graduate programs who require their students to complete hands-on experiences with AAC systems could also be in response to literature (e.g., Koul \& Llyod, 1994; Ratcliff \& Beukelman, 1995; Ratcliff, Koul, \& Llyod, 2008; Costigan \& Light, 2010) that has implored graduate programs to provide more comprehensive preservice education in AAC to graduate students in speech-language pathology; or in response to literature (e.g., Marvin et al., 2003) that has utilized clinician testimony to make a case for the need for more comprehensive preservice education experiences in AAC. 
When asked to describe the greatest barriers that graduate programs face in providing comprehensive coursework in AAC, respondents cited limited access to AAC systems, student's coursework schedules and meeting all of the requirements to complete ASHA's criteria for clinical certification, limited faculty members with expertise in AAC, and funding as the primary barriers. However, it is important to note that some of these barriers overlap with one another and can influence each other. For example, it is possible that some graduate programs have limited funding available, which creates limitations in employing faculty members with expertise in $\mathrm{AAC}$, acquiring and maintaining $\mathrm{AAC}$ systems and devices, and providing scholarships and training grants for graduate students to further their education in AAC. Additionally, these barriers can have a cyclical nature, wherein factors continue to affect one another. For example, limited funding can influence the number of AAC devices a graduate program can acquire and maintain, which may influence the number of faculty members with expertise in AAC that are drawn to work at that program and may limit the amount of funding the graduate program can receive to improve their preservice AAC climate.

When compared to previous literature on coursework in AAC, this data from the current study indicate that there has been an improvement in the number of graduate programs offering dedicated coursework in AAC, which can likely be attributed to the shift in ASHA's requirements for clinical certification from a requirement in "communication modalities" to a requirement in "AAC." Additionally, despite reported barriers in funding and acquisition and maintenance of AAC systems and devices, there has been in increase in the number of graduate programs who infuse some form of hands-on experiences with AAC systems into their coursework requirements.

\section{Clinical Experiences in AAC}

Clinical experiences in AAC at the preservice level allow for collaboration with and learning from clinical faculty trained in AAC, which allows for better education and preparation for later field work in AAC. Preservice clinical experiences in AAC may be related to later competencies in AAC, which may improve the quality of service that a speech-language pathologist can provide to clients with 
complex communication needs. Therefore, clinical experiences in AAC are vital to ensuring that speechlanguage pathologists can implement appropriate assessment and treatment plans, problem-solve technology failures, and generate creative solutions to provide AAC to clients with complex and/or severe/multiple disabilities.

A majority of participants $(63 \%)$ indicated that at least half of students who graduated from their program earned at least some clinical clock hours in AAC. This is a marked increase from the previous literature, where between 1995 and 2008, approximately 75\% of students in responding graduate programs received no clinical practicum experiences in AAC. It is possible that this increase has come as a result of an increase in the population of individuals who use or need AAC, or because of an increase in public awareness about AAC and the individuals who could benefit from the use of AAC. It is also possible that this increase could be in response to the recent change in ASHA's requirements for clinical certification to specifically require experiences in "AAC," as opposed to "communication modalities." Additionally, another possible contributor to the increase in the number of students who earn clinical clock hours in AAC could be due to technology advancements and number of AAC systems available to clinicians and universities as well as the number of clients who may be served by a university clinic that houses AAC systems for assessments and interventions. However, it is important to note that this survey did not evaluate the average number of clinical clock hours obtained by graduate students, and therefore, there could be great variability in the amount of clinical experience in AAC that graduate students are receiving in their preservice education.

It is important to note that this survey did not assess the quality of these clinical experiences, and thus, it is difficult to determine if there is a true improvement in this area of preservice education in AAC. For example, this survey did not evaluate the average number of clinical clock hours that students receive in AAC, nor the faculty supervisor overseeing the clinical experiences in AAC or student perceptions of the quality of their clinical experiences in AAC. Consequently, there is possibily great variability in the quality of clinical experiences being provided to graduate students in AAC, despite the increased number 
of students who graduate with clinical clock hours in AAC. There is current literature on self-perceptions of knowledge and skills in AAC that indicates that practicing speech-language pathologists report feeling inadequately prepared to serve clients with AAC needs (e.g., Marvin et al., 2003). Thus, it is possible that, despite the increase in the quantity of individuals who are receiving preservice clinical experiences in AAC, there might be a need for additional focus on the quality of these clinical experiences in AAC to ensure that future clinicians are prepared to work with individuals who use or could benefit from AAC.

When asked to report the setting(s) in which their graduate students participated in clinical experiences in AAC, $18 \%$ of responses indicated that these experiences took place in university clinicsmore than any other clinical settings. However, a free-response question about barriers to the provision of clinical experiences in AAC highlighted that the most common barrier was due to the low-incidence of individuals who use AAC in their clinical settings. It is possible that the number of clinical opportunities in AAC in university clinics are limited, and therefore, some students may graduate from preservice education programs in speech-language pathology without obtaining clinical experiences in AAC. This inference was corroborated by a free-response question in which participants revealed that it can be difficult to ensure that all students have access to a clinical placement that provides learning opportunities in $\mathrm{AAC}$, and that this is a barrier to the provision of comprehensive clinical experiences in AAC.

This inability to provide clinical experiences in AAC to all graduate students may mean that some future clinicians are inadequately prepared to work with clients with complex communication needs. This can have a myriad of negative impacts for both the speech-language pathologist and their clients with complex communication needs. For instance, clients with complex communication needs who are not provided with clinically competent AAC assessment and intervention services may be more likely to: a) experience difficulty fully participating in social and vocational experiences, b) be segregated or isolated from typically-developing peers in the educational setting, and c) have difficulty securing gainful employment opportunities and participating in activities of daily living as inferred from Light \& McNaughton (2015). 
Similarly, it is possible that individuals with complex communication needs who are not receiving sufficient services in AAC are more prone to device abandonment. Device abandonment is defined by ASHA (n.d., p. 27) as when an individual stops using their AAC device, even though a device or system is still necessary for the individual to meet their daily communication needs. ASHA (n.d., p. 27) has outlined some factors that contribute to device abandonment, which includes client "frustration due to lack of AAC knowledge on the part of the professional.” ASHA (n.d., p. 27) also outlines suggestions to reduce abandonment, some of which include: a) a good match between the device and the client's language, physical, and cognitive abilities, b) collaboration with the individual and their family to incorporate their needs and values into the assessment process, and c) thorough intervention and training is provided to the individual who uses AAC and their communication partners. As indicated, some of these outlined factors that contribute to device abandonment can be alleviated by ensuring that the speech-language pathologist who conducts an AAC assessment and provides AAC intervention services to the client possesses adequate knowledge and skills in AAC and can implement those knowledge and skills in their clinical practice. Therefore, it can be concluded that when clinicians possess adequate knowledge and skills in AAC, they are better able to provide clinically competent services to their clients, which thereby increases their communicative, academic, and social success, as well as ensuring their quality of life.

Eighty-eight percent of respondents stated that their graduate program had AAC systems to be used for clinical and coursework experiences. However, nearly $41 \%$ of responses from participants cited funding and access to AAC devices and systems as barriers to providing comprehensive clinical experiences in AAC. Although "funding" is a vague term that could be responsible for a variety of barriers that a graduate program may be experiencing, it may also influence a program's ability to obtain and maintain a variety of AAC systems. It is possible that although many graduate programs have AAC systems, they have difficulty maintaining range of low-tech, mid-tech, and high-tech AAC systems. They may also have difficulty keeping these devices up-to-date and acquiring the newest AAC systems. If the 
AAC systems that the graduate program has available for coursework and clinical opportunities are on loan from AAC vendors and/or outside agencies the graduate program may have difficulty acquiring their own AAC systems. These themes were paralleled by respondents whose graduate programs did not possess AAC systems. These respondents overwhelmingly cited funding and financial burdens as the primary barrier to obtaining AAC systems, as well as rapidly changing technology and obsolete devices as additional barriers.

Despite these reported barriers, it is important for graduate programs to take every measure to secure AAC systems for students to use or provide opportunities for students to gain hands-on experiences with AAC systems and technology, to ensure that these future clinicians can practice using these systems with support from faculty members and/or other students. This kind of hands-on practice with AAC systems increases the likelihood that clinicians will feel more comfortable programming and implementing a variety of AAC systems, which ultimately benefits their clients with complex communication needs. For example, clinicians with hands-on experience and operational competencies with a variety of AAC systems may be more likely to be able to conduct an ethical AAC assessment using a feature-matching process and clinical trials with different systems. Additionally, clinicians with handson experiences in AAC may be more likely to be able to troubleshoot technology malfunctions, program vocabulary and device settings, and serve as a technology resource for families and other professionals when problems arise.

However, clinicians who did not receive hands-on experiences and training in their preservice education program may not feel comfortable using or discussing a variety of AAC systems, which can lead to negative outcomes for a client and their family. For example, clinicians who do not feel comfortable using a variety of systems and technology, or those who are not aware of a variety of systems and technology, may be more likely to prescribe an AAC system without conducting a full evaluation to determine the best system that fits the unique skills and needs of that client. Additionally, clinicians with limited hands-on experiences in AAC may fail to provide clinically-competent intervention services to 
their clients or defer these services to another speech-language pathologist or an affiliated occupational therapist. Furthermore, without these competencies and hands-on experiences with AAC systems, clinicians may be more likely to avoid AAC altogether, thereby doing an extreme disservice to clients with complex communication needs. All of these factors ultimately contribute to the communicative success — or lack thereof — of the individual who uses AAC. Therefore, hands-on experiences with AAC systems at the preservice level increase the likelihood that future clinicians will be able to serve their clients more effectively in their clinical practice.

In 2008, Ratcliff, Koul, \& Llyod reported that $46 \%$ of the responding 168 graduate programs in speech-language pathology revealed that less than $25 \%$ of students who left their program were prepared to work with clients with AAC needs upon graduation. Results from the current study indicate that there has been an increase in the number of students who leave a graduate program in speech-language pathology with knowledge and skills in AAC. When asked to approximate the percentage of students who leave from their program with knowledge and skills in AAC, $78 \%$ of programs reported that $76-100 \%$ of their students graduate with knowledge and skills in AAC. However, it is important to note that characteristics of these knowledge and skills were not explored further, and there was no measurement for the depth of knowledge and skills that these students have acquired. Therefore, it is possible that some students graduate with minimal or limited knowledge and skills in AAC given that the criterion for answering this question was simply acquiring any knowledge and skills in AAC.

Survey results indicated that there are a variety of barriers impacting the provision of comprehensive clinical experiences in AAC, including: a) faculty members with expertise in AAC, b) acquisition and maintenance of AAC systems and devices, c) availability of sufficient amounts of clinical placements that provide exposure to AAC, and d) funding, which may impact a variety of other factors. It is also possible that other factors may be influencing the provision of clinical experiences in AAC that were not assessed in this survey (e.g., student interest in AAC). Therefore, it is difficult to determine what barriers are most prominent, and which barriers require the most immediate attention to improve 
preservice clinical experiences in AAC. It is likely that many graduate programs are experiencing multiple barriers to providing comprehensive clinical experiences in AAC, which may make it more challenging to overcome said barriers. As multiple barriers build on each other, graduate programs may perceive that these barriers are too difficult to overcome, thereby leading to negative attitudes about preservice education in AAC or contributing to the number of practicing clinicians who perceive that they received inadequate preservice education in $\mathrm{AAC}$ and are ill-prepared to work with clients who use or could benefit from AAC.

\section{Faculty Members}

The most recent literature evaluating faculty expertise in AAC has indicated that many graduate programs fail to employ a faculty member with adequate or significant expertise in AAC. In Costigan and Light's (2010) literature review, they found that $54-71 \%$ of graduate programs surveyed in previous studies did not employ a single faculty member with notable expertise in AAC. Data from the current study reveals that $47 \%$ of programs have at least one academic faculty member with a primary expertise in AAC, and $43 \%$ of programs have at least one clinical faculty member with a primary expertise in AAC. This data parallels the findings from Costigan \& Light (2010), which indicates that the field is still in great need of additional academic and clinical faculty members with expertise in AAC.

Seventeen percent of programs reported that they have two or more academic faculty members with primary expertise in AAC, and $42 \%$ of programs reported that they have two or more clinical faculty members with primary expertise in AAC. When asked to report the individual(s) responsible for teaching coursework in AAC, $89 \%$ of respondents revealed that this responsibility fell upon a faculty member with at least some explicit expertise in AAC. Although it is positive that the majority of programs have appointed this responsibility to a faculty or staff member with some familiarity in AAC, it is important to note that this study did not assess the depth of knowledge and skills in AAC held by these individuals. Thus, it is possible that different respondents used different criteria to qualify their employee's expertise in AAC, which may be reflected in the data results. 
While there has been an increase in the number of graduate programs who employ a faculty member with some expertise in AAC, there is still a great need for additional faculty members with expertise in AAC. Data from this study suggests that nearly $36 \%$ of graduate programs of varying sizes still do not employ a single academic or tenure-track faculty member with a primary expertise in AAC. Similarly, $32 \%$ of graduate programs of varying sizes do not employ a clinical faculty member with a primary expertise in AAC.

It is possible that the lack of faculty members with expertise in AAC may be negatively contributing to the overall climate of preservice education in AAC. This need for additional faculty members with expertise in AAC can have a range of impacts on preservice education in AAC, including: a) difficulty securing university or federal funds to purchase and maintain AAC systems, b) difficulty securing federal funding for personnel preparation grants in AAC and c) the possibility of insufficient or noncomprehensive academic and clinical experiences for graduate students, as they may be learning from a faculty member who does not feel confident in the most current evidence-based practices in AAC service provision. Additionally, it is possible that this lack of faculty members with expertise in AAC may have an even larger impact on clinical competencies in AAC that new professionals possess than has been originally considered. For example, limited numbers of faculty with expertise in AAC may mean that some graduate students are receiving insufficient preservice education in AAC through coursework and clinical experiences, which may mean that they have difficulty providing services in AAC to their clients that yield positive outcomes. Furthermore, this may limit the number of clinicians who choose to return to higher education to pursue a doctoral degree in AAC, which limits the number of faculty members with expertise in AAC teaching future professionals, thereby perseverating the cyclical pattern, and continuing the trend of limited faculty members with expertise in AAC.

Thus, although the data suggests an improvement in the number of graduate programs who employ a faculty member with expertise in AAC, there is still a great need for additional faculty members with expertise in AAC. It is possible that an increased number of faculty members with expertise in AAC 
could greatly improve the climate of preservice education in AAC, as well as overall clinical service provision to individuals who use and need AAC.

\section{Additional Learning Opportunities in AAC}

Thirteen percent of participants stated that their graduate program currently had an AAC training grant, and nineteen percent of participants stated that their graduate program had previously had an AAC training grant. Participants also noted that securing federal funding to purchase and update AAC systems is a challenge, and it is possible that it is also difficult for graduate programs to secure federal funding grants for training grants and personnel preparation grants. Without this kind of funding and the faculty members with expertise in AAC available to carry out the training grants, it can be challenging to initiate these types of programs. However, these programs can be beneficial to our field for a variety of reasons, including: a) increasing the number of clinicians who possess a deep, strong knowledge base in AAC, and those clinicians can pass that knowledge base to other professionals, b) increasing the likelihood that students will develop a passion for AAC and later return to higher education to pursue a $\mathrm{PhD}$ in $\mathrm{AAC}$ and pass that knowledge along to future students, c) student funding and scholarships associated with training grants and personnel preparation programs can increase the number of students who are able to pursue a master's degree in speech-language pathology, and d) positive outcomes for clients who use AAC and their communication partners.

\section{Implications}

This study was designed to evaluate the current characteristics of preservice education in AAC taking place at graduate programs in speech-language pathology to evaluate strengths and areas for improvement. Preservice education programs around the nation could use the data gathered in this study to improve their provision of preservice education in AAC to graduate students. Speech-language pathologists employed in a variety of work environments are likely to encounter clients who use or need $\mathrm{AAC}$ and should possess adequate knowledge and skills in $\mathrm{AAC}$ assessment and intervention to ensure 
the communicative success of these individuals. Graduate programs in speech-language pathology have a responsibility to prepare their students with clinically competent knowledge and skills in AAC through coursework, clinical opportunities, and other learning opportunities in AAC.

Graduate programs have expressed that they face barriers in providing these knowledge and skills for a variety of reasons, including funding, limited faculty with expertise in AAC, student schedules, challenges in accessing a variety of AAC systems and devices, limited clinical experiences in AAC available to students, and limited access to clients who use or need AAC in their clinical settings. In order to overcome some of these barriers, graduate programs in speech-language pathology should consider alternative options to creating opportunities for students to gain knowledge and skills in AAC. For example, graduate programs can build relationships and partner with local AAC vendor representatives to establish a long-term loaner system for devices so students are able to have access to a range of devices during their clinical and coursework experiences. These relationships with AAC vendor representatives could also lead to opportunities for graduate students to observe or complete an independent study working with these vendor representatives to learn about AAC and provide support to individuals with complex communication needs and their families. These types of observation and independent study experiences might provide opportunities for additional students to gain some hands-on experiences with AAC devices, which is important given that many graduate programs noted that they face a barrier in ensuring that all students have access to a clinical experience with clients who use AAC.

Additionally, with the increase in telepractice and virtual meetings, graduate programs could use these technologies to create additional learning opportunities. The provision of telepractice services for AAC treatment has not been well-established but has the possibility to increase the access that graduate programs have to clients who use AAC. Furthermore, telepractice holds promise for providing services to individuals who require AAC services but are unable to access them due to proximity or other barriers. It also has the possibility to reduce caseload size and ensure that clinically competent services are being provided to clients with complex communication needs, as practitioners with very high caseloads and/or 
limited knowledge and skills in AAC could refer clients to graduate programs for telepractice treatment in AAC. Additionally, graduate programs could utilize this technology to collaborate with other programs and faculty members to improve the quantity and quality of provided preservice learning opportunities in AAC. For instance, graduate programs that do not have a faculty member with expertise in AAC on staff could utilize virtual meeting venues to bring in guest lecturers with a strong expertise in AAC in coursework or seminars. Similarly, graduate programs with a strong foundation in AAC could collaborate with graduate programs that are still working to develop or implement AAC opportunities to provide online learning opportunities and workshops to that program's students and faculty members. Technology can be an excellent avenue to begin to overcome some of the reported barriers to the provision of comprehensive preservice education in AAC.

Graduate programs should work to identify and address barriers that they may be facing in providing high-quality preservice education in AAC to its students and consider creative avenues to overcoming those barriers whenever possible. Provision of high-quality preservice education in AAC to graduate students increases the likelihood that they will be able to provide clinically competent services to individuals with complex communication needs and ensure the communicative success of those individuals.

\section{Limitations}

The limitations of this study include a low response rate (approximately 34\%), the graduate programs' reporting of data for all questions, the respondents' familiarity with the preservice education opportunities at their graduate program, the wording of survey questions and responses, and the generalization of results to all graduate programs. Additionally, because participation in this survey was optional, it is possible that the respondents who chose to participate are employed by graduate programs that have strong preservice education opportunities in AAC. Survey data is from the perspective of the graduate programs, not by students who graduate from their program, which may be accompanied with 
biased reporting of data. It is possible that students who graduate from these graduate programs might hold different perspectives on the quality of their preservice education in AAC.

Surveys were sent to department chairs, program directors, clinic directors, and professors at graduate programs around the nation. Although participants were instructed to pass the survey along to the most qualified individual to complete the survey, it is possible that some respondents were not closely involved with their program's preservice education in AAC. Free-response questions indicated that some respondents may not have had the adequate or correct information about the characteristics of their program's preservice education in AAC to answer some of these questions. The respondents' lack of knowledge about the opportunities that their graduate program provides in AAC may have affected their ability to provide accurate information. Additionally, some participants' answers to free-response questions indicated that the wording of questions and their associated answers may have been redundant or confusing, which may have altered the types of responses that participants gave.

Finally, the return rate for this survey was approximately $34 \%$, so these results cannot be generalized to all graduate programs in speech-language pathology. Because "AAC" is in the title of the survey, it is possible that participants who did not feel as though they possess adequate knowledge and skills in AAC, or that their graduate program had room for improvement in the provision of preservice education in AAC chose not to participate in the study, thereby possibly skewing results to look more positive than they actually are. When the investigator called 100 random programs to encourage completion of the survey, some points of contact misunderstand the purpose of the survey and disregarded the soliciting emails before opening or looking at the survey. Some individuals noted that they had previously thought the survey was intended to evaluate their own levels of expertise in AAC, as opposed to defining characteristics of the program. Therefore, it is possible that the low response rate could be attributed to confusion about the intents of the study, as well as participant hesitance to report their own levels of expertise in AAC. 


\section{Future Research}

This research should be expanded to a larger sample size, and to include more in-depth questions to evaluate preservice education in AAC and its associated challenges to better determine suggestions for improvement. These types of data are essential to improving the knowledge and skills of future clinicians in the area of AAC. Future research is needed to evaluate the quality of coursework, clinical experiences, and other learning opportunities to determine how these experiences may facilitate the development of clinical skills in AAC that have ties to concrete application in the careers of working speech-language pathologists.

Future research should focus on comparing perspectives of graduate programs and clinicians who have graduated from graduate programs in speech-language pathology to determine if current preservice education practices adequately prepare clinicians to work with clients who use or need AAC. This comparison would allow more a more accurate evaluation of the acquisition of knowledge and skills in AAC in students' preservice education programs and may aid in the identification of additional barriers and suggestions for improvement that were not evaluated in this study. Additional evaluations of student perspectives and outcomes would be beneficial to future research. 


\section{References}

American Speech-Language-Hearing Association (n.d.): Augmentative and Alternative Communication (Practical Portal). Retrieved March, 25, 2018, from www.asha.org/Practice-Portal/ProfessionalIssues/Augmentative-and-Alternative-Communication/.

American Speech-Language-Hearing Association (n.d., b). Augmentative and Alternative Communication (AAC). Asha.org. Available from: https://www.asha.org/public/speech/disorders/AAC/

American Speech-Language-Hearing Association (2016). Scope of practice in speech-language pathology. Asha.org. Available from www.asha.org/policy/.

American Speech-Language-Hearing Association (2016b). Code of ethics. Asha.org, Available from: http://www.asha.org/Code-of-Ethics/

American Speech-Language-Hearing Association (2014). 2014 Standards and implementation procedures for the certificate of clinical competence in speech-language pathology. Asha.org. Available from: https://www.asha.org/certification/2014-speech-language-pathology-certificationstandards/

American Speech-Language-Hearing Association (2012). CFCC standards for certification in speechlanguage pathology comparison. Asha.org. Available from: https://www.asha.org/uploadedFiles/2005-2014-SLP-Standards-Comparison.pdf

Beukelman, D. \& Mirenda, P. (2013). Augmentative and alternative communication: supporting children and adults with complex communication needs. Baltimore, MD: Brookes.

Binger, C., Ball, L., Dietz, A., Kent-Walsh, J. Lasker, J., Lund, S., McKelvey, M., \& Quach, W. (2012). Personnel roles in the AAC assessment process. Augmentative and Alternative Communication. 28(4). 278-288.

Binger, C. \& Light, J. (2006). Demographics of preschoolers who require AAC. Language, Speech, and Hearing Services in Schools. 37. 200-208.

Clinical Innovation and Governance (2016). Augmentative and alternative communication (AAC): Guidelines for speech pathologists who support people with disability.

Costigan, A., \& Light, J. (2010). A review of preservice training in augmentative and alternative communication for speech-language pathologist, special education teachers, and occupational therapists. Assistive Technology. 22. 200-212.

Cumley, G., \& Beukelman, D. (1992). Roles and responsibilities of facilitators in augmentative and alternative communication. Thieme Medical Publishers.

Enderby, P., Pickstone, C., John, A., Fryer K., Cantrell, A., \& Papaioannou, D. (2009). Resource manual for commissioning and planning services for SLCN. Royal College of Speech \& Language Therapists. https://www.rcslt.org/speech_and_language_therapy/commissioning/aac_plus_intro 
Johnson, J., Ingelbret, E., Jones, C., \& Ray, J. (2006). Perspectives of speech language pathologists regarding success versus abandonment of AAC. Augmentative and Alternative Communication. 22(2). 85-99.

Koul, R., \& Llyod, L. (1994). Survey of professional preparation in augmentative and alternative communication (AAC) in speech-language pathology and special education programs. American Journal of Speech-Language Pathology. 3(3). 13-22.

Light, J., Drager, K., Currall, J., \& Roberts, B. (2012). Preservice training of speech-language pathologists in evidence-based AAC services. Presentation at the American Speech-LanguageHearing Association (ASHA) Convention in: Atlanta, Georgia.

Light, J., \& McNaughton, D. (2012). Supporting the communication, language, and literacy development of children with complex communication needs: state of the science and future research priorities. Assistive Technology. 24. 34-44.

Light, J., \& McNaughton, D. (2014). Communicative competence for individuals who require augmentative and alternative communication: a new definition for a new era of communication? Augmentative and Alternative Communication. 30. 1-18. doi: 10.3109/07434618.2014.885080

Light, J., \& McNaughton, D. (2015). Designing AAC research and intervention to improve outcomes for individuals with complex communication needs. Augmentative and Alternative Communication. 31(2). 85-96. doi: $\underline{10.3109 / 07434618.2015 .1036458}$

Marvin, L., Montano, J., Fusco, L., \& Gould, E. (2003). Speech-language pathologists' perceptions of their training and experience using alternative and augmentative communication. Contemporary Issues in Communication Science and Disorders. 30. 76-83.

National Joint Committee for the Communication Needs of Persons with Severe Disabilities (2003). Position statement on access to communication services and supports: concerns regarding the application of restrictive "eligibility" policies (position statement). Available from: www.asha.org/policy

Ratcliff, A., \& Beukelman, D. (1995). Preprofessional preparation in augmentative and alternative communication: state-of-the-art report. Augmentative and Alternative Communication. 11. 61-73.

Ratcliff, A., Koul, R., \& Llyod, L. (2008). Preparation in augmentative and alternative communication: an update for speech-language pathology training. American Journal of Speech-Language Pathology. 17. 48-59.

Simpson, K., Beukelman, D., \& Bird, A. (1998). Survey of school speech and language service provision to students with severe communication impairments in Nebraska. Augmentative and Alternative Communication. 14. 212-221. 


\section{Appendix A}

Survey of Preservice Education in AAC: An Update

\section{Information Statement}

The Department of Speech-Language-Hearing at the University of Kansas supports the practice of protection for human subjects participating in research. The following information is provided for you to decide whether you wish to participate in the present study. You should be aware that even if you agree to participate, you are free to withdraw at any time without penalty. We are conducting this study to better understand preservice education and training in augmentative and alternative communication (AAC) provided to graduate students in Masters of Speech-Language Pathology programs. This will entail your completion of a survey. Your participation is expected to take approximately 10-15 minutes to complete. The content of the survey should cause no more discomfort than you would experience in your everyday life. Although participation may not benefit you directly, we believe that the information obtained from this study will help us gain a better understanding of the characteristics of preservice education and training in AAC for graduate students in Speech-Language Pathology. Your participation is solicited, although strictly voluntary. Your name will not be associated in any way with the research findings. Your identifiable information will not be shared unless (a) it is required by law or university policy, or (b) you give written permission. It is possible, however, with internet communications, that through intent or accident someone other than the intended recipient may see your response. If you would like additional information concerning this study before or after it is completed, please feel free to contact us by phone or mail. Completion of the survey indicates your willingness to take part in this study and that you are at least 18 years old. If you have any additional questions about your rights as a research participant, you may call (785) 864-7429 or write the Human Research Protection Program (HRPP), University of Kansas, 2385 Irving Hill Road, Lawrence, Kansas 66045-7563, email irb@ku.edu.

Sincerely,

Kate DeJarnette

Principal Investigator

Department of Speech-Language Hearing

2101 Haworth Hall

University of Kansas

Lawrence, KS 66045

(785) 864-4690

kate.dejarnette@ku.edu
Jane Wegner, Ph.D.

Faculty Supervisor

Department of Speech-Language Hearing

2101 Haworth Hall

University of Kansas

Lawrence, KS 66045

(785) 864-4690

jwegner@ku.edu

I am at least 18 years old and understand the risks and benefits of this survey. I am willing to take part in this study.

I am not 18 years old

I am not willing to take part in this study

\section{Demographics}


1. Please indicate your position in the graduate program.

Department Chair

Program Director

Academic Faculty Member

Clinical Faculty Member

Staff Member

Other: Please Specify

2. In what state is your graduate program located?

Alabama (1) ... Puerto Rico (51)

3. For how many years has your university had a graduate program in speech-language pathology?

$0-9$ years

10-19 years

20-29 years

$30+$ years

4. For how many years has your graduate program in speech-language pathology been accredited by the Council on Academic Accreditation (CAA)?

$0-9$ years

10-19 years

20-29 years

$30+$ years 
5. How many faculty members (e.g., total number of academic/tenure-track faculty, clinical supervisors, and adjunct faculty), are employed by your graduate program in speech-language pathology?

$0-2$

$3-5$

$6-9$

$10-14$

$15+$

6. On average, how many students are enrolled in your graduate program in speech-language pathology (include all students enrolled in the program)?

$0-14$

$15-29$

$30-44$

$45-59$

$60+$

\section{Coursework in AAC}

7. Does your graduate program offer coursework in AAC?

Yes

No 
8.Are graduate students required to take a course in AAC?

\section{Yes \\ No}

9. Does your graduate program offer a dedicated course in AAC (e.g., a course with primary focus in AAC)?

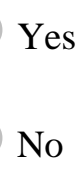

10. If your graduate program offers a dedicated course in AAC, for how long have you offered this course?

11. If your graduate program offers a dedicated course in AAC (e.g., a course with primary focus in AAC), how many dedicated courses are offered? 
12. On average, what percentage of students who graduate from your program have taken a dedicated course in AAC (e.g., a course with primary focus in AAC) during their graduate program?

$0-25 \%$

$26-50 \%$

$51-75 \%$

$76-100 \%$

13. If your graduate program does not offer dedicated coursework in AAC, how does your program provide opportunities for completion of this area of knowledge and skills for its students? Select all that apply.

\section{Clinical Experiences}

Content infused into other courses

Continuing Education Credits (CEUs)

Other: Please specify

N/A, my graduate program does offer dedicated coursework in AAC

14. Does your graduate program infuse AAC content into non-dedicated courses (e.g., a course that includes AAC content, but does not have a primary focus in AAC)?

Yes

No

15. If your graduate program infuses AAC content into non-dedicated courses, please list the courses which include this content. 
16. On average, what percentage of students who graduate from your program have taken a non-dedicated course in AAC (e.g., a course that includes AAC content, but does not have a primary focus in AAC) during their graduate program?

$0-25 \%$ of students

$26-50 \%$ of students

$51-75 \%$ of students

$76-100 \%$ of students

17. Approximately how much classroom time is devoted to AAC in non-dedicated courses?

Approximately 1 hour of classroom time

Approximately 2 hours of classroom time

Approximately 3 hours of classroom time

Approximately 4 to 6 hours of classroom time

More than 7 hours of classroom time 
18. Describe the type(s) of readings required in dedicated and/or non-dedicated AAC coursework. Select all that apply.

Journal articles, but no textbook

Textbook(s), but no journal articles

Both textbook(s) and journal articles

Online resources (websites, blogs, etc.)

None

19. What is the course format/delivery for both dedicated and non-dedicated AAC courses? Please select all that apply.

On-site classroom and/or laboratory

Hybrid course: on-site classroom component and online component

Online format only

Other: Please Specify 
20. Please select all persons that are responsible for teaching coursework in AAC.

Faculty member with clinical experience in AAC

Faculty member with research experience in AAC

Faculty members without clinical experience in AAC

Faculty members without research experience in AAC

Doctoral student with experience in AAC

Doctoral student without experience in AAC

Adjunct faculty member with experience in AAC

Adjunct faculty member without experience in AAC

Graduate teaching assistant 
21. Does your graduate coursework include information about AAC assessment?

Yes

Maybe

No

Skip To: Q12 If Does your graduate coursework include information about AAC assessment? = No

22. Please describe the content and topic areas of AAC assessment that are included in graduate coursework. 
23. Does your graduate coursework include information about AAC intervention?

\section{Yes}

\section{Maybe}

No

Skip To: Q13 If Does your graduate coursework include information about AAC intervention? = No

24. Please describe the content and topic areas of AAC intervention that are included in graduate coursework. 
25. Does your graduate coursework include hands-on experiences with AAC systems?

Yes

Maybe

No

Skip To: Q38 If Does your graduate coursework include hands-on experiences with AAC systems? = No

26. Please describe the types of hands-on experiences with AAC systems offered to students in their coursework.

27. Please describe the greatest barrier(s) to providing comprehensive coursework in AAC.

Access to AAC systems or devices

Faculty members with limited expertise in AAC

Funding

Student's coursework schedules

Other, please describe. 


\title{
Clinical Experiences in AAC
}

28. Does your graduate program offer clinical/hands-on experiences in AAC to its students?

\author{
Yes \\ No
}

Skip To: Q19 If Does your graduate program offer clinical/hands-on experiences in AAC to its students? = No 
29. What types of clinical/hands-on experiences are available to students to learn AAC technology? Select all that apply.

Students observe instructor demonstrate activities and/or technology

Students get hands-on experience, but no requirements for operational competency of AAC systems

Students are required to demonstrate specific operational competencies of AAC technology

Other (please describe)

None

30. Please describe the settings that graduate students participate in clinical experiences in AAC. Select all that apply.

University Clinic

Inpatient Hospital Setting

Outpatient Hospital Setting

Community Clinic

Skilled Nursing Facility

Private Practice

Home Health

School

Rehabilitation Setting

31. Does your graduate program provide clinical experiences in AAC service provision to multicultural populations?

Yes. Please describe. 
Maybe

No

32. Please describe the populations of individuals who use AAC that students serve in their clinical experiences. Select all that apply.

Pediatrics with developmental disabilities

Pediatrics with acquired disabilities

Adults with developmental disabilities

Adults with acquired disabilities

Geriatrics with developmental disabilities

Geriatrics with acquired disabilities

33. If your graduate program does not offer clinical experiences in AAC, please describe the barrier(s) to providing these clinical experiences to students.

34. Of the total number of students who leave your graduate program to enter into speech-language pathology, approximately what percent of graduates earn clinical clock hours in AAC as part of their clinical practicum, fieldwork, and/or externship experience(s)?

$0-25 \%$ of students

$26-50 \%$ of students

$51-75 \%$ of students

$75-100 \%$ of students 
35. Does your graduate program have AAC systems to be used for clinical and coursework experiences?

Yes

No

Skip To: Q42 If Does your graduate program have AAC systems to be used for clinical and coursework

experiences? $=$ No

36. How many AAC systems does your graduate program have?

37. Please describe the AAC systems that your graduate program has (e.g., level of technology, manufacturer make and model, etc. Example: High-tech PRC Accent 1200 and TobiiDynavox T10).

38. If your graduate program does not have AAC systems, please describe the process by which your graduate program acquires AAC systems to be used for clinical and coursework experiences.

39. If your graduate program does not have AAC systems, please describe the challenges faced in acquiring the systems.

40. Approximately what percentage of your graduate students acquire knowledge and skills in the area of AAC (e.g., assessment, documentation, development and intervention of AAC, evaluation of AAC outcomes and effectiveness, advocacy, and coordination of AAC services)?

$0-25 \%$

$26-50 \%$

$51-75 \%$

$76-100 \%$

41. In regards to knowledge and skills in the area of AAC (e.g., assessment, documentation, development and intervention of AAC, evaluation of AAC outcomes and effectiveness, advocacy, and coordination of 
AAC services), please select which knowledge and skills are most difficult for your graduate students to earn.

Knowledge and skills in AAC assessment

Knowledge and skills in AAC intervention

Knowledge and skills in AAC assessment and intervention

42. Please describe the greatest barrier(s) to providing comprehensive clinical experiences in AAC. Select all that apply.

Access to AAC systems or devices

Faculty members with limited expertise in AAC

Access to clients who use AAC

Funding

Other, please describe.

\section{Faculty Members}


43. How many academic or tenure-track faculty members have AAC as a primary area of expertise?
0
1
$2-3$
4-5
6 or more

44. How many academic or tenure-track faculty members have AAC as a secondary area of expertise?
0
1
$2-3$
4-5
6 or more

45. How many academic or tenure-track faculty members have AAC as a minimal area of expertise?
0
) 1
2-3
4-5
6 or more 
46. How many clinical faculty members or supervisors have AAC as a primary area of expertise?
0
1
$2-3$
4-5
6 or more

47. How many clinical faculty members or supervisors have AAC as a secondary area of expertise?
0
1
$2-3$
4-5
6 or more

48. How many clinical faculty members or supervisors have minimal knowledge and skills in AAC?
0
1
2-3
4-5
6 or more

Additional Learning Opportunities in AAC 
49. Does your graduate program offer additional experiences for graduate students to gain AAC practice in the field (outside of clinical practicum experiences)?

Yes. Please specify.

No

50. Does your graduate program currently have AAC training grants (e.g., funding opportunities for students in the area of AAC)?

Yes

No

51. Has your graduate program previously had AAC training grants (e.g., funding opportunities for students in the area of AAC)?

Yes

No

52. Please describe the greatest barrier(s) to providing comprehensive preservice education and/or training in AAC to graduate students in your program. Select all that apply.

Access to AAC systems or devices.

Faculty members with limited expertise in AAC

Limited availability of clinical experiences/opportunities in AAC

Funding, please describe.

Other, please describe. 
53. Please indicate if you are comfortable with a researcher contacting you or another faculty member of your graduate program with follow-up questions at a later date. If yes, please specify a preferred contact person, their email address and/or phone number.

Yes. Please provide additional information.

No 